NBER WORKING PAPER SERIES

THE RECENT GROWTH BOOM IN DEVELOPING ECONOMIES:

A STRUCTURAL CHANGE PERSPECTIVE

\author{
Xinshen Diao \\ Margaret McMillan \\ Dani Rodrik \\ Working Paper 23132 \\ http://www.nber.org/papers/w23132 \\ NATIONAL BUREAU OF ECONOMIC RESEARCH \\ 1050 Massachusetts Avenue \\ Cambridge, MA 02138 \\ February 2017
}

We acknowledge Peixun Fang for excellent research assistance. Diao and McMillan gratefully acknowledge the support of the CGIAR's research program Policies, Institutions, and Markets (PIM) led by the International Food Policy Research Institute. The views expressed herein are those of the authors and do not necessarily reflect the views of the National Bureau of Economic Research.

NBER working papers are circulated for discussion and comment purposes. They have not been peer-reviewed or been subject to the review by the NBER Board of Directors that accompanies official NBER publications.

(C) 2017 by Xinshen Diao, Margaret McMillan, and Dani Rodrik. All rights reserved. Short sections of text, not to exceed two paragraphs, may be quoted without explicit permission provided that full credit, including $\odot$ notice, is given to the source. 
The Recent Growth Boom in Developing Economies: A Structural Change Perspective Xinshen Diao, Margaret McMillan, and Dani Rodrik

NBER Working Paper No. 23132

February 2017

JEL No. O1,O11,O4

\begin{abstract}
$\underline{\text { ABSTRACT }}$
Growth has accelerated in a wide range of developing countries over the last couple of decades, resulting in an extraordinary period of convergence with the advanced economies. We analyze this experience from the lens of structural change - the reallocation of labor from low- to highproductivity sectors. Patterns of structural change differ greatly in the recent growth experience. In contrast to the East Asian experience, none of the recent growth accelerations in Latin America, Africa, or South Asia was driven by rapid industrialization. Beyond that, we document that recent growth accelerations were based on either rapid within-sector labor productivity growth (Latin America) or growth-increasing structural change (Africa), but rarely both at the same time. The African experience is particularly intriguing, as growth-enhancing structural change appears to have come typically at the expense of declining labor productivity growth in the more modern sectors of the economy. We explain this anomaly by arguing that the forces that promoted structural change in Africa originated on the demand side, through either external transfers or increase in agricultural incomes. In contrast to Asia, structural change was the result of increased demand for goods and services produced in the modern sectors of the economy rather than productivity improvements in these sectors.

Xinshen Diao

Development Strategy and

Governance Division

International Food Policy

Research Institute

2033 K Street NW

Washington, DC 20006

x.diao@cgiar.org

Margaret McMillan

Tufts University

Department of Economics

114a Braker Hall

Medford, MA 02155

and International Food Policy Research Institute

and also NBER

margaret.mcmillan@tufts.edu

Dani Rodrik

John F. Kennedy School of Government

Harvard University

79 J.F. Kennedy Street

Cambridge, MA 02138

and NBER

dani_rodrik@harvard.edu
\end{abstract}




\title{
The Recent Growth Boom in Developing Economies: A Structural-Change Perspective
}

\author{
Xinshen Diao, Margaret McMillan, and Dani Rodrik \\ January 2017
}

\section{Introduction}

Developing countries have experienced an extraordinary period of economic development over the last couple of decades. Beside India and China, which registered record economic growth rates, countries in Sub-Saharan Africa and Latin America have managed to match or exceed their performance of the 1960s and first half of the 1970s. The recent downturn in the global economy has cast a dark shadow on the future of this performance, and Latin America in particular has been badly hit by the decline in commodity prices. But growth in the low-income countries of Africa has been resilient and remains high.

Even a cursory look at the experience of the recent growth champions indicates that their experience differs greatly from the standard East Asian path. East Asian countries such as South Korea, Taiwan, and China grew through rapid export-oriented industrialization. By contrast, none of the recent growth experiences outside East Asia show evidence of rapid industrialization. Instead, Latin American countries have experienced premature de-industrialization, while in Africa manufacturing industries are barely holding their own in most countries.

How do we understand this recent wave of economic growth in developing countries? What have been the main drivers, and how sustainable are they? We offer a structuralist perspective on this recent experience, focusing on the role of structural change in driving economywide labor productivity growth. In East Asian countries, the movement of labor from low-productivity agriculture and informality to modern manufacturing industries and associated activities played a critical role. Was there a similar transformation in the recent crop of growth accelerations? Even if industrialization did not play a substantial role, did the expansion of other modern activities such as services, substitute for it? And what has been the relationship between patterns of structural change and labor productivity growth within specific sectors or the "within" component of economywide labor productivity growth?

We begin by reviewing and updating some of the stylized facts in McMillan and Rodrik (2011) on structural dualism in developing nations and relating the structuralist perspective to the neoclassical growth model (section 2). We then turn to recent episodes of growth acceleration in Latin America, Africa, 
and India (section 3). We decompose labor productivity growth during these episodes into two terms: within-sector productivity growth and inter-sectoral labor reallocation.

Our most interesting finding is that recent growth accelerations were based on either rapid withinsector labor productivity growth (Latin America) or growth-increasing structural change (Africa), but rarely both at the same time (section 4). There is a strong negative correlation between the two components of growth across countries, with India as the sole exception. In Latin America, within-sector labor productivity growth has been impressive, but growth-promoting structural change has been very weak. In fact, structural change has made a negative contribution to overall growth excluding agriculture, meaning labor has moved from high-productivity sectors to low-productivity activities. In Africa, the situation is the mirror image of the Latin American case. Growth-promoting structural change has been significant, especially in Ethiopia, Malawi, Senegal, and Tanzania. But this has been accompanied in these countries by negative labor productivity growth within non-agricultural sectors.

We also show in section 4 that this experience stands in sharp contrast with the classic East Asian growth experience (such as in South Korea and China), in which both components of labor productivity contributed strongly to overall growth. Moreover, the East Asian pattern seems to be replicated in more recent Asian cases of growth accelerations as well (in Bangladesh, Cambodia, Laos, and Vietnam, and India as mentioned earlier).

The Latin American pattern of weak or negative structural change was noted and discussed in McMillan and Rodrik (2011), and related to the region's commodity dependence, overvalued exchange rates, (relatively) low agricultural employment shares, and de-industrialization. But the African pattern is puzzling. Rapid growth-promoting structural change has become a feature of the African economic landscape - something that was not evident in the data in McMillan and Rodrik (2011) - which is surely good news. It is also somewhat surprising, given that industrialization has not figure prominently in the region. But it now comes at the expense of declining labor productivity growth in the more modern sectors of the economy. How can we make sense of this anomaly?

We develop a simple two-sector general equilibrium model in section 5 to shed light on regional patterns of structural change, especially the contrast between the African and Asian models. We make specific assumptions on preferences, namely that demand is non-homothetic (with a declining budget share of the traditional sector) and the modern sector good is price elastic. We show that the Asian pattern of strong "within" and "between" components is consistent with growth being driven mainly by 
positive productivity shocks to the modern sectors. The model generates a positive correlation between the two components of aggregate labor productivity growth: as the modern sector expands thanks to the positive productivity shock, it draws labor from the other, less-productive sectors of the economy.

The African model, by contrast, is consistent with growth being driven not by the modern sector, but by positive aggregate demand shocks (due to foreign transfers, for example) or by productivity growth in the traditional sector (agriculture). In this model, the modern sector expands and growthpromoting structural change takes place as increased demand spills over to the modern sector. (Our assumptions on preferences ensure that demand shifts are sufficiently biased towards the modern sector to ensure the modern sector expands in both cases, despite relative-price adjustments.) But labor productivity in the modern sector is driven down as a by-product, as diminishing returns to capital set in and less productive firms are drawn in. This is also consistent with the relatively poor performance of manufacturing in Africa.

These considerations suggest that positive structural change in African countries may be driven mainly from the demand side, whether due to external transfers or the induced demand effects from increased agricultural incomes. This in turn raises the question of the sustainability of recent growth, an issue we discuss in the concluding section.

\section{Structural Dualism and Labor Productivity Growth}

The concept of structural dualism has its roots in development economics and the work of Lewis (1954). This work draws a sharp distinction between the traditional and modern sectors of the economy; accumulation, innovation, and productivity growth all take place in the modern sector while the traditional sector remains technologically backward and stagnant. Thus, economywide growth depends largely on the rate at which resources-principally labor-can migrate from the traditional to the modern sector. The reason that this concept is still so important in the context of developing countries is because the economies of today's poor countries are still very much characterized by structural dualism. The implication of this dualism is that there are potentially large payoffs to moving workers out of the traditional sector and into the modern sector.

Of course an emphasis on structural dualism does not imply that there is no role for the neoclassical growth model first introduced by Solow (1956). But it is the process of structural change whereby resources flow from less to more productive activities that tends to fuel rapid growth in the 
earliest stages of development. By contrast, in neoclassical models, growth depends on the incentives to save, accumulate physical and human capital, and (in subsequent variants that endogenize technological change) innovate by developing new products and processes (Grossman and Helpman 1991; Aghion and Howitt 1992). The two channels may have common determinants. For example, improved incentives to invest and adopt new technologies in the modern sector may enable the sector to expand and absorb labor from the traditional sector. But the two models emphasize different processes as being critical to growth.

These traditions offer complementary perspectives on economic growth (Rodrik 2014). One way to combine their insights is to think of the neoclassical model as essentially focusing on the growth process within modern sectors, while the dual-economy model focuses on relationships and flows among sectors. Each perspective provides a distinct logic behind growth in the lagging countries. In what follows we first present evidence which strongly suggests that dualism is alive and well in developing countries. We then lay out our conceptual framework for thinking about the sources of growth that incorporates both the dual economy and neo-classical models of growth.

\section{A. Structural dualism: the data}

Our evidence on structural dualism is based on the 10-sector database produced by researchers at the Groningen Growth and Development Center (GGDC). We use the most recent version of the data which were last updated in January 2015 (Timmer, de Vries, and de Vries 2015). These data consist of sectoral and aggregate employment and real value-added statistics for 30 developing countries and 9 high-income countries covering the period up to 2010 and, for some countries, to 2011 or 2012 . The countries and their geographical distribution are shown in Table 1, along with some summary statistics. We compute labor productivity by dividing each sector's real value added by the corresponding level of sectoral employment. The sectoral breakdown we use in the rest of the paper is shown in Table 2.

Using the GGDC data to compute average labor productivity by sector raises some important measurement issues. The first has to do with the extent to which the GGDC data accounts for the informal sector. The data for value-added come from national accounts, and as mentioned by Timmer and de Vries (2007, 2009), the coverage of such data varies from country to country. While all countries make an effort to track the informal sector, obviously the quality of the data can vary greatly. On employment, Timmer and de Vries $(2007,2009)$ relied on population censuses for total employment levels and their sectoral distribution; they used labor force surveys for the growth in employment 
between census years. Census data and other household surveys tend to have more complete coverage of informal employment. In short, a rough characterization of the data would be that the employment numbers in the GGDC dataset broadly coincide with actual employment levels, regardless of formality status, while the extent to which value-added data include or exclude the informal sector heavily depends on the quality of national sources. For a detailed explanation of the protocols followed to compile the GGDC 10-Sector database, refer to Timmer, de Vries, and de Vries (2015) and "Sources and Methods" at the database's web page: http://www.ggdc.net/databases/10 sector.htm.

The second concern -- and one that has gotten a lot of attention in recent literature ${ }^{1}-$ - is that the quality of the data collected by national statistical agencies in poor countries and Africa in particular is not very good. Like Diao, Harttgen and McMillan (2017) our confidence in the estimates of value added at the sectoral level is bolstered by the following facts. First, the African countries included in the GGDC database are the countries in Africa with the strongest national statistical offices and these countries have been collecting national accounts data for some time. Second, researchers at the GGDC specialize in providing consistent and harmonized measures of sectoral value added and our view is that this expertise lends credibility to these numbers. Finally, using LSMS surveys, researchers have shown that sectoral measures of value added based on national accounts data are highly correlated with sectoral measures of consumption (Gollin, Lagakos, and Waugh 2014).

The third concern stems from the measurement of labor inputs. Ideally, instead of using the measured number of workers employed in a sector, we would use the number of hours worked in a sector. This would correct for biases associated with the seasonality of agriculture that might lead to an underestimation of agricultural labor productivity. This is a serious issue and for the purposes of this paper, we rely on work by Duarte and Restuccia (2010) who show that in a sample of 29 developed and developing countries the correlation between hours worked and employment shares is close to one and Gollin, Lagakos, and Waugh (2014) who show that correcting labor productivity measures for hours worked does not overturn the result that labor productivity in agriculture is significantly lower than labor productivity in the rest of the economy. Note that this does not mean that there are not off-farm

\footnotetext{
${ }^{1}$ See for example Klasen and Blades (2013).
} 
activities in rural areas that bring in less income for example than farming. In fact, this is highly likely in very poor economies where a large share of economic activity is of a subsistence nature. ${ }^{2}$

Finally, the productivity gaps we describe here are differences in average labor productivity. When markets work well and structural constraints do not bind, it is productivities at the margin that would be equalized. Under a Cobb-Douglas production function specification, the marginal productivity of labor is the average productivity multiplied by the labor share. Thus, if labor shares differ greatly across economic activities, then comparing average labor productivities can be misleading. The fact that average productivity in mining is so high, for example, simply indicates that the labor share in this capital-intensive sector is quite small. In the case of other sectors, however, there does not appear to be a clearly significant bias. Once the share of land is taken into account, for example, it is not obvious that the labor share in agriculture is significantly lower than in manufacturing (Mundlak, Butzer, and Larson 2012). Therefore, the large observed differences in average labor productivity between manufacturing, say, and agriculture do point to large gaps in marginal productivity.

\section{B. Structural dualism: the evidence}

Figure 1 shows that for the 11 African countries in the GGDC sample, the productivity gaps across sectors are indeed enormous. ${ }^{3}$ Each bin in the figure corresponds to one of the nine sectors in the dataset, ${ }^{4}$ with the width of the bin corresponding to the sector's share of total employment, and the height corresponding to the sector's labor productivity level as a fraction of average labor productivity in the economy. Agriculture, at 35 percent of average productivity, has the lowest productivity by far; manufacturing productivity is 1.7 times as high, and mining productivity is 16.8 times as high.

Furthermore, the figure makes evident that the majority of employment in the African sample is in the most unproductive sectors, with roughly two-thirds of the labor force in the two sectors with belowaverage productivity (agriculture and personal services). Based on this figure, it appears that the potential for structural change to contribute to labor productivity growth is still quite large in most African countries.

That productivity gaps in Africa are large is not surprising. It is evident from Table 1 that the least productive countries in our sample are in Africa. In previous work (McMillan and Rodrik, 2011), we

\footnotetext{
${ }^{2}$ Using LSMS-ISA data McCullough (2015) finds that correcting for hours worked reduces the gap between labor productivity in agriculture and in other activities significantly but she provides no explanation for the large difference between her results and the results of Gollin, Lagakos, and Waugh (2014).

${ }^{3}$ We use Africa in this paper to refer to the 11 Sub-Saharan African countries included in the GGDC Database.

${ }^{4}$ Figure 1 excludes government services.
} 
showed that these productivity gaps tend to shrink as countries get richer. We provide updated evidence on this relationship in Figure 2. The coefficient of variation is recorded on the vertical axis and the log of real value added per worker is recorded on the horizontal axis. Not surprisingly, extending the sample to 2010 does not alter our main insight; as countries get richer the gaps in labor productivity across sectors shrinks. The implication is that there is relatively more scope for achieving labor productivity gains in poor countries by moving labor out of agriculture and into other more productive sectors.

The way this process evolves tells us something important about the process of development. McMillan and Rodrik (2011) documented that the productivity gap between the agricultural and nonagricultural sectors of the economy follow a U-shaped relationship. The economic logic behind this relationship is intuitive. In very poor countries with few modern industries the productivity gap between agriculture and the rest of the economy is low. As new activities start to take place in the modern sector the gap starts to widen and the economy becomes more dual (Kuznets, 1955). As labor starts to move from the traditional sector to the modern sector productivity starts to converge between the two sectors. As noted by McMillan and Rodrik (2011) this story highlights two key dynamics of structural transformation: the rise of new industries (i.e. economic diversification) and the movement of resources from traditional industries to these new industries. Without the first, there is little that propels the economy forward. Without the second, productivity gains don't diffuse in the rest of the economy.

Of course these are broad patterns in the data and our story is about the way things should work if the process of development is on track. If we dig a little bit deeper, we can learn more about how the process of structural change is evolving across countries. To do this, we start with a little bit of algebra that clarifies the forces at work described in the previous paragraph. Let the relative productivity of the agricultural sector (RPA) be defined as follows:

$$
R P A=\frac{\operatorname{Lprody}_{A}}{\operatorname{Lrrody}_{N}}=\frac{V A_{A}}{L_{A}} / \frac{V A_{N}}{L_{N}}=\frac{V A s_{A}}{V A s_{N}} / \frac{L s_{A}}{L s_{N}}
$$

where $V A s_{i}=\frac{V A_{i}}{G D P}$ and $L s_{i}=\frac{l_{i}}{l}$ denote shares of value added and employment in sector i respectively.

What happens to the RPA over the course of development? To understand this, we focus on the last term in equation (1). The rise of new industries increases value added in the nonagricultural sector which on its own lowers the numerator causing the RPA to fall. At the same time however, attracted by new opportunities in the nonagricultural sector, labor exits agriculture and the employment share in 
agriculture falls which in turn raises relative labor productivity in the agricultural sector. Thus, the RPA only falls in the early stages of development when productivity growth in the nonagricultural sector outpaces the countervailing forces which work to raise the RPA.

Very few countries in our sample actually fit this pattern but they are big countries. Figure 3 shows that this happened in China and India but for different reasons. ${ }^{5}$ In China, very rapid productivity growth in manufacturing occurred alongside structural change. As Wei and Zhang (2011) have shown, the bulk of this productivity growth was a result of the entry of new private firms into the manufacturing sector. This rapid productivity growth in manufacturing outpaced labor exits from agriculture thereby lowering the RPA. By contrast, in the case of India, recent rapid productivity growth in the modern services sector (e.g., IT) outpaced shifts in employment shares primarily because such modern services employ relatively few workers and so employment shares did not change all that much.

The more typical pattern in the data for a developing country is a long period (20-40 years) where the counterbalancing forces keep the RPA fairly constant. We show this pattern for Chile and Thailand in Figure 4. In the case of Thailand, the RPA hovered around 0.10 for almost 40 years and it is only in the past 10 years or so that it has started to inch upward at a level of economywide labor productivity over 10,000 PPP USD. The pattern is not that different for Chile although the data for Chile start at a much higher income level. In general, the RPA only starts to increase when shifts in employment from agriculture to nonagriculture become minimal and agricultural labor productivity growth starts to outpace productivity growth in the nonagricultural sector. This pattern can be seen for the United States in Figure 4 and is typical of the developed countries in our sample. But it is also evident in a number of middle income developing countries in Asia and Latin America.

A different pattern seems to be emerging in a number of poor African countries. We show this pattern for Ethiopia, Malawi and Tanzania in Figure 4. In all three countries, the RPA seems to be trending upward but at very low levels of economywide labor productivity. Since we know that the employment share in agriculture has fallen over time in these three countries, the trend upward in the RPA implies that labor productivity in agriculture is growing more rapidly than labor productivity in the nonagricultural sector. This is the same pattern we see in developed countries but at much higher levels of income. In poor countries like Ethiopia, Malawi and Tanzania, we expect labor productivity in the

\footnotetext{
${ }^{5}$ The RPA also fell in Nigeria but this is driven solely by extremely high productivity in the oil sector without any meaningful structural changes.
} 
modern sector to grow more rapidly than or at least at the same rate as labor productivity in agriculture. We return to this point later in the paper.

\section{A formalization of the two growth traditions}

While structural dualism is clearly an important feature of developing countries, a complete accounting of labor productivity growth must take into account the fact that labor productivity growth can be achieved in one of two ways. First, productivity can grow within existing economic activities through capital accumulation or technological change. Second, labor can move from low-productivity to high-productivity activities, increasing overall labor productivity in the economy. Following McMillan and Rodrik (2011) we express these two components of labor productivity growth using the following decomposition:

$$
\Delta y^{t}=\sum_{i} \theta_{i}^{t-k} \Delta y_{i}^{t}+\sum_{i} y_{i}^{t} \Delta \theta_{i}^{t}
$$

where $y^{t}$ and $y_{i}^{t}$ refer to economywide and sectoral labor productivity levels, respectively, and $\theta_{i}^{t}$ is the share of employment in sector $i$. The $\Delta$ operator denotes the change in productivity or employment shares between $\mathrm{t}-k$ and $t$ and $t>k$. The first term in the decomposition is the weighted sum of productivity growth within individual sectors, where the weights are the employment share of each sector at the beginning of the period. As in McMillan and Rodrik (2011), we call this the "within" component of productivity growth. The second term captures the productivity effect of labor reallocations across different sectors. It is the inner product of productivity levels (at the end of the period), with the change in employment shares across sectors. We call this second term the "structural change" term.

The second term in equation (2) could be further decomposed into a static and dynamic component of structural change, as in de Vries, Timmer and de Vries (2015). We choose not to go that route here because the dynamic component of the structural change term is often negative and difficult to interpret. For example, when agricultural productivity growth is positive and the labor share in agriculture is falling, the term is negative, even though, on average, the movement of workers out of agriculture to other more productive sectors of the economy makes a positive contribution to structural change and economywide labor productivity growth. Moreover, structural change is, by its very nature, a dynamic phenomenon; thus, we find it counterintuitive to label a part of structural change static. 
The decomposition we use clarifies how partial analyses of productivity performance within individual sectors (for example, manufacturing) can be misleading when there are large differences in labor productivities $\left(y_{i}^{t}\right)$ across economic activities. In particular, a high rate of productivity growth within a sector can have ambiguous implications for overall economic performance if the sector's share of employment shrinks rather than expands. If the displaced labor ends up in activities with lower productivity, economywide growth will suffer and may even turn negative. This has been an important reason for poor economywide productivity growth in Latin America, where modern sectors have performed very well, but without expanding their share of the economy's labor force (McMillan and Rodrik 2011).

This decomposition can be used to study broad patterns of structural change within a country and across countries. An example of this type of analysis can be found in McMillan and Rodrik (2011). We provide a brief discussion of growth decomposition methodologies and the method used in this paper in the Appendix. Individual components of the decomposition such as labor shares and withinsector changes in productivity can also be used at the country level to dig deeper into where structural change is or is not taking place and to gain a deeper understanding of the country-specific factors that drive structural change. For example, if we know that the expansion of manufacturing is a characteristic of structural change in a particular country, we could use more detailed data on manufacturing to pinpoint which specific industries expanded, how many people were employed, and whether specific events or policies contributed to the expansion or contraction of a particular sector. For country-specific analyses of this type, refer to Structural Change, Fundamentals, and Growth: A Framework and Country Studies (forthcoming), edited by McMillan, Rodrik, and Sepulveda.

\section{Identification of Growth Accelerations}

We use data from the Penn World Tables (PWT) 9.0 to compute annualized growth rates and to identify growth accelerations for the Latin American and African countries included in the GGDC's 10 sector database. Our definition of a growth acceleration is based on a slightly modified version of the filter applied by Hausmann, Pritchett and Rodrik (2005) - heretofore HPR. Instead of examining annualized growth in GDP per capita over an eight-year period, we limit ourselves to a seven year period since our analysis is primarily focused on recent growth episodes. Thus, we will say that a country has experienced a period of growth acceleration if it satisfies the following three conditions:

(3) $\quad g_{t, t+n} \geq 3.5 p p a-$ growth is rapid; 


$$
\begin{aligned}
& \Delta g_{t}=g_{t, t+n}-g_{t-n, t} \geq 2.0 \text { ppa-growth accelerates; } \\
& y_{t+n} \geq \max \left\{y_{i}\right\}, i \leq t-\text { post-growth output exceeds pre-episode peak; }
\end{aligned}
$$

where the relevant time horizon is seven years (i.e., $n=6$ ).

We summarize the timing and nature of these growth accelerations in Table 3. Column (1) of Table 3 indicates the year in which the growth acceleration started for each country. Columns (2) and (3) show the average annual growth rates in the pre and post acceleration periods respectively. In column (4) we report the difference between the pre and post acceleration growth rates. In column (5) we indicate whether post-growth output exceeds the pre-episode peak. In column (6), we report the growth rate following the initial seven years of each growth episode. The numbers in column (6) indicate that with the exception of Venezuela countries in Africa and Latin America have continued to grow mostly at a rapid pace - following the initial period of growth acceleration.

It is evident from Table 3 that most countries satisfy the three conditions in Equations (3)-(5) but there are some exceptions. Rather than dropping countries from the analysis, we modify the filter so as to include all Latin American and African countries in our analysis. For 8 countries -4 in Latin America and 4 in Africa - that do not satisfy the first condition in Equation (3) we lower the cutoff to 2.0 ppa. Additionally, in 7 out of 20 countries the level of per capita GDP in the first year of growth acceleration has not yet exceeded the pre-episode peak. We keep these countries and indicate the year in which this happens in column (6) of Table 3. Finally, in the last row of Table 3 we report statistics for India because unlike the rest of Asia, India's growth take-off is relatively recent. Although it started to pick up speed in 1983 and it has become more rapid in the 1990s and 2000s.

To check the robustness of the results reported in Table 3, we use GDP per capita data from the World Development Indicators (WDI) and value added per worker data from the Groningen Growth and Development Center (GGDC). The results of this comparison are reported in Table 4. In column (1) we repeat the initial year of the growth acceleration based on the data in Table 3. Although not reported in Table 4, we do find that the two data sources produce identical initial years for the start of the growth acceleration in almost all of the countries while it is off by only 1 or 2 years for a few countries. Thus our comparisons are based on the initial year of the acceleration identified using the PWT data. In columns (2)-(4) we report annualized growth rates in the 7 years leading up to the growth acceleration based on PWT, WDI and GGDC and in columns (5)-(7) we report these same growth rates during the period of the 
7-year growth acceleration. In columns (8)-(10) we report the difference in growth rates between the pre- and post-acceleration periods based on the numbers in columns (2)-(7).

The PWT and WDI data show similar growth rates before and during the growth episodes for all countries except Mexico. For Mexico, the WDI data show a much lower growth rate over the growth episode identified using the PWT (1.57\% versus $2.28 \%)$ and a smaller difference in growth rates pre- and post-growth acceleration (1.04\% versus $2.40 \%$ ). We nevertheless keep Mexico in our sample since in the growth decomposition analysis, the within versus between components may still be informative.

By contrast, a comparison between growth in GDP per capita and growth in value added per worker or labor productivity growth using the (GGDC) data reveals that labor productivity growth rates are comparable to GDP growth rates albeit slightly lower. However, Mexico and Venezuela are exceptions. Labor productivity growth in Mexico is negative during the post-growth acceleration phase while per capita GDP growth rate using PWT and WDI data is positive. And labor productivity growth in Venezuela is much lower than growth in GDP per capita. Overall, however, the differences in labor productivity growth over the two periods are comparable to those of GDP per capita growth. This is important because when we decompose growth into its' within and between components we use the GGDC data.

\section{Structural Change During Growth Accelerations}

\section{A. Comparing patterns in Africa and Latin America}

To better understand both the sources and sustainability of the growth accelerations we identified in Section 3, we decompose labor productivity growth into its' within and between components. We use the GGDC data for this analysis and the methodology laid out in Section 2 for the growth decomposition. We examine both the pre and post acceleration periods as defined in Table 3 . For the purpose of analyzing shifts in patterns of labor productivity growth, we extend the time horizon on either side of the break by three years so that in essence we study the growth decomposition in the 10 years leading up to the growth acceleration and in the 10 years following the growth acceleration.

We begin with broad patterns and then dig into country specifics. Figure 5 summarizes the growth decompositions by region and income status. We include India as a separate "region" for purposes of comparison. Labor productivity growth is reported along the horizontal axis and ranges from around minus 1 percent to close to 3 percent. The bars are coded according to how much of labor 
productivity growth comes from structural change (in vertical black lines) and how much comes from within sector labor productivity growth (in diagonal gray lines). As can be seen in Figure 5, the income groups correspond almost exactly to the regional groupings since most of the low-income countries are in Africa. We exclude Venezuela from this analysis because its' growth was not sustained (see Table 3). We also exclude Botswana and Mauritius on the grounds that they do not belong in our group of "late" growth accelerations (see Table 3, first column).

Figure 5 shows the much higher labor productivity growth post-growth acceleration periods in all regions and income groups and the low or negative labor productivity growth rates during pregrowth acceleration periods. This is as expected and is by design. Turning to the growth decomposition, we can see that for Africa, both the within-sector and structural change components of labor productivity growth are negative prior to the acceleration while labor productivity growth is close to zero in Latin America. During the period after the growth acceleration, structural change contributes significantly to growth in Africa but only minimally to growth in Latin America. This is not surprising since we expect the payoff to structural change to be greatest in poor countries. India differs from both regions in that the difference between the economywide labor productivity growth rates pre- and postacceleration is more modest and the contribution of structural change is much greater during the relatively high growth period.

Figure 6 is a scatter plot of the relationship between within-sector labor productivity growth (horizontal axis) and the labor productivity growth that arises as a result of structural change (vertical axis). Country details are reported in Table A1. The most important pattern revealed by Figure 6 is the negative correlation between within-sector labor productivity growth and the labor productivity growth that comes from structural change. This pattern of growth is intriguing, as it contrasts with the Asian growth experience in which within-sector productivity growth and structural change both contributed positively - and strongly - to aggregate productivity growth during the post-growth acceleration period (see Figure A1). In other words, recent high growth experiences in Africa and Latin America have been based on either high productivity growth within sectors, or rapid, growth-promoting structural change, but rarely both at the same time. We will return to this anomaly and possible explanations later in the paper. The details of the various country experiences can also be seen in Figure 6 and fall broadly in line with the aggregate patterns reported in Figure 5.

Figure 7 presents the relationship between within-sector labor productivity growth and structural change in the period after the growth acceleration relative to the period leading up to the 
growth acceleration. The relationships depicted in Figure 7 are most closely associated with the second HPR filter for identifying growth accelerations since they tell us something about the relative importance of the structural change and within-sector components of labor productivity growth in pushing a country toward a growth acceleration. Once again, there is a strong negative correlation between the within and structural change components of growth among the countries whose labor productivity growth acceleration is modest $(-0.839)$. But the negative relationship seems to hold only weakly among the countries with rapid growth acceleration (-0.375), and does not hold anymore for all countries taken together (-0.194).

Since sustained economic growth is closely associated with both an expansion of modern sector activities and productivity growth within the non-agricultural sector, we examine each of these contributions to economywide labor productivity growth. This helps us to gauge the relative importance of each of these contributions to labor productivity growth in Latin America and Sub-Saharan Africa. We present this growth decomposition result by region and for India in Figure 8. Labor productivity growth rates are reported along the horizontal axis; within agricultural sector labor productivity growth is shaded with diagonal lines, within nonagricultural sector labor productivity growth is shaded with a chess board pattern, and the labor productivity growth coming from structural change is shaded with vertical black lines.

Figure 8 shows that the labor productivity growth attributable to each of the within components of growth in Africa combined is lower than within sector labor productivity growth in the nonagricultural sector alone in Latin America. For Latin America, there is no within agricultural sector productivity growth and structural change also contributes little to economywide productivity growth. In fact, the structural change component is negative for Latin America as a whole if we focus on nonagriculture only. ${ }^{6}$ The latter finding implies that labor has moved from more productive subsectors to less productive subsectors within nonagriculture during the period of relatively high growth in Latin America. Deindustrialization partly explains this pattern as the service sectors have expanded to absorb the workers displaced from the manufacturing sector. India is similar to Latin America in terms of showing strong within-sector productivity growth in the nonagricultural economy. But unlike Latin America, structural change has also played a role in India.

Figure 8 displays only regional averages. At the level of individual countries, we may expect to see different patterns. Indeed, Chile and Peru, the Latin American countries with the most rapid

\footnotetext{
${ }^{6}$ The decomposition of structural change into agriculture and nonagriculture was not shown in Figure 8.
} 
economywide labor productivity growth during the period of relatively high growth $(4.13 \%$ and $4.03 \%$, respectively, see Table A1) are characterized by strong contributions from both the within nonagricultural sector component of labor productivity growth and the structural change component. However, for the rest of the countries in Latin America the pattern is similar to the regional average. There is a strong negative correlation between productivity growth within the nonagricultural sector and structural change (-0.892) across these countries; this negative correlation disappears when Chile and Peru are added.

For some African countries, the rapid economywide productivity growth post-growth acceleration is even higher than in Chile and Peru. For example, the economywide labor productivity growth rate is $4.65 \%$ for Ethiopia and $4.23 \%$ for Tanzania in the period after the growth acceleration (see Table A1). However, the negative correlation between labor productivity growth within the nonagricultural sector and the labor productivity growth as a result of structural change remains negative even when these two countries are included (correlation coefficient is -0.888 for all the 10 African countries and is -0.920 when Ethiopia and Tanzania are excluded).

\section{B. Digging deeper: strong structural change with weak nonagricultural productivity growth in Africa}

The within-sector and structural change components of productivity growth in African countries are plotted in Figure 9 across multiple nonagricultural subsectors for the post-growth acceleration period. We include the following six private nonagricultural subsectors in the figure if they have positively contributed to aggregate labor productivity growth through structural change: manufacturing, construction, trade services, transport services, business services and personal services. We also include manufacturing sectors that have negatively contributed to structural change but have experienced positive within sector labor productivity growth. We exclude mining, utilities, and government services since these are not sectors which can be expected to contribute in a meaningful way to economywide labor productivity growth.

The figure suggests that we can classify the countries included into two groups:

\section{Group 1: Strong structural change with negative productivity growth in the nonagricultural} sector. The countries in this group are Ethiopia, Malawi, Senegal and Tanzania. The six nonagricultural sectors for these four countries are shown with dots in Figure 9.

Group 2: Weak structural change. The following four countries fall into this group: Ghana, Kenya, Nigeria and South Africa. Their sectors are represented with squares in Figure 9. 
We observe a large negative correlation coefficient between productivity growth within sector (x-axis) and structural change (y-axis) (-0.721) for the countries in Group 1, indicating the sectors that positively contribute to structural change are often those that experienced declines in within-sector labor productivity. The manufacturing sector follows a similar pattern for at least three of the countries in this group. For the countries in Group 2, there exists a weak negative correlation between modest structural change and within-sector labor productivity growth (with coefficient of -0.246).

Table 5 provides more details on within-sector productivity growth for nonagricultural subsectors that contribute positively to structural change in the four Group 1 countries. While expansion of manufacturing does contribute overall to these countries' labor productivity growth (the structural change term), labor productivity growth within manufacturing tends to be either negative or close to zero.

An alternative way of looking at these patterns is to focus on correlations across countries for individual nonagricultural subsectors. This is done in Table 6, which shows the correlation between the structural change term and within-sector productivity growth across different countries, sector by sector. We consider five nonagricultural sub-sectors here and Figure 10 displays the relationship in a scatter plot. The preponderance of negative correlations is striking, especially for Group 1 countries. Once again, sectors that contribute strongly to structural change-led growth tend to be the ones that do worse in terms of within-sector productivity growth.

\section{African versus Asian patterns of structural transformation}

For purposes of comparison, we present similar information for five Asian countries during their first 10 years after their initial growth accelerations in Figure 11. The countries covered are those included in the GGDC dataset. In contrast to the African, Figure 9 shows that the Asian countries exhibit a positive correlation between the within and structural change components of labor productivity growth. In other words, in Asia well-performing nonagricultural sectors have contributed to economywide productivity growth both by drawing labor from lower-productivity sectors and by experiencing rapid productivity improvements.

Could these patterns be due to differences in the timing of growth accelerations? Using the same HPR filter and data from the PWT 9.0, we identify four low-income Asian countries which experienced growth accelerations starting in the 1990s or early 2000s; these are Bangladesh, Cambodia, Lao and Vietnam. Since these countries are not included in the GGDC dataset, we instead use value- 
added data from the United Nations Statistics Division (UNSD) website and employment data from the International Labor Organization (ILO). These data allow us to decompose output and employment among three broad sectors only: agriculture, industry and services. We note that manufacturing tends to dominate employment and value added in these countries. A second limitation is that the ILO provides sectoral employment data only for the 2003-2014 period. Apart from Bangladesh all of these countries experienced their growth accelerations during the 1990s. Nevertheless, since growth accelerated and the industrial share of employment continued to increase in the 2000s for all four countries, we rely on 2003-2014 data to examine their post-acceleration growth patterns.

The results are shown in Figure 12. In all four countries, the within-sector component of productivity growth was the largest contributor to overall labor productivity growth, but the structuralchange component was also positive and made a substantial contribution in at least three of the four cases. Looking specifically at the role of the nonagricultural sectors as we did before, we find that with almost no exception, industry and services contributed significantly to both the within and structural change components of labor productivity growth (Figure 13).

The main conclusion we can draw from these numbers is that when structural change contributed significantly to overall growth as it did in all four low income Asian countries, it was not at the expense of poor productivity performance in the expanding sectors as in Africa. As we saw earlier, this is also the case for the earlier rapidly industrializing countries such as Korea and China in Asia, but also Mauritius in Africa.

In the next section, we develop a model that attempts to further explain the intriguing differences between African and Asian countries in the aftermath of growth accelerations. Here we simply note that the Asian comparison does raise concerns about the sustainability of the recent African growth experience. While structural change is strong and has led to rapid productivity growth in African countries, it has been accompanied by weak to negative performance in within sector productivity growth in the non-agricultural sectors of the economy. ${ }^{7}$ If this trend were to continue, the gap in labor productivity between high productivity nonagricultural sectors and the agricultural sector would shrink prematurely. i.e., while these countries still remain relatively poor. This would in turn lead to a decline in overall growth potential and limit the role of growth-inducing structural change in the future.

\footnotetext{
${ }^{7}$ Timmer et al. (2015) have pointed earlier that sectors that expanded their employment shares tended to have productivity growth rates below those of shrinking sectors over the 1990-2010 period. The same point is also made in starker form in the African context in de Vries et al. (2015).
} 


\section{A Simple Economic Framework}

In this section we develop a simple economic model to help us interpret the pattern of correlations we discussed previously. Our focus is on understanding the relationship between various types of demand and supply side shocks, on the one hand, and patterns of structural change and withinsector labor productivity performance, on the other. In particular, what might explain the difference between the Asian pattern and the more recent African pattern? In the former, high productivity sectors that expanded also experienced high rates of productivity growth, whereas in the latter expanding highproductivity sectors have experienced poor productivity growth.

We will stress that this and other related asymmetries are likely the result of differences in the nature of the shocks driving growth in the two regions. In Asia, it was the expansion of modern sectors (especially manufacturing) that acted as the engine of growth. In the more recent growth accelerations in Africa, the impetus came not from manufacturing or the modern parts of the economy, but from positive demand shocks or productivity growth in agriculture.

We divide the economy into traditional and modern sectors, identified by subscripts $t$ and $m$. In terms of the classification we used before, agriculture is the main traditional sector, while urban services and manufacturing comprise the modern sector.

Production functions in the two sectors are written as

$$
\begin{gathered}
y_{t}=\theta_{t} g\left(1-l_{m}\right) \\
y_{m}=\theta_{m} f\left(l_{m}\right)
\end{gathered}
$$

where $y_{t}$ and $y_{m}$ are the outputs of the two sectors, $l_{m}$ is the share of the economy's employment in the modern sectors, and $f($.$) and g($.$) are neoclassical production functions with f^{\prime}, g^{\prime}>0$ and $f^{\prime \prime}, g^{\prime \prime}<0$. The parameters $\theta_{m}$ and $\theta_{t}$ are shifters that will allow us to do comparative statics for supply-side shocks in different parts of the economy. Denoting the relative price of modern goods by $p$, aggregate output (GDP) is

$$
y=y_{t}+p y_{m}
$$

We allow total expenditures in the economy to differ from GDP so that we can perform comparative statics also around demand-side shifts. We express total expenditures, $z$, as the sum of GDP and an external transfer, $b$. 


$$
z=y+b
$$

On the side of consumer preferences, we posit a Stone-Geary type utility function so that demand patterns will be non-homothetic between traditional and modern goods. In addition, we assume demand for the modern good is price elastic. If $\sigma_{t}$ is the "subsistence" level of the traditional good, expenditures on the modern good is expressed as:

$$
p c_{m}=\gamma(p)\left(z-\sigma_{t}\right)
$$

where $c_{m}$ is the physical consumption level of the modern good and $\gamma^{\prime}(p)<0$. Note that the budget share of the modern good increases with total expenditures $z$, since $\frac{p c_{m}}{z}=\gamma(p)\left(1-\frac{\sigma_{t}}{z}\right)$. In the limit, when $z$ becomes very large relative to the subsistence consumption $\sigma_{t}$, the budget share of the modern good converges from below to $\gamma(p)$. And since $\gamma^{\prime}(p)<0$, this budget share is also decreasing in the relative price of the modern sector. Demand for the goods produced by the traditional sector is correspondingly written as

$$
c_{t}=\sigma_{t}+(1-\gamma(p))\left(z-\sigma_{t}\right)
$$

Note that the budget constraint $c_{t}+p c_{m}=z$ is satisfied.

We need to express market-clearing for at least one of the sectors, which we do for the modern one:

$$
c_{m}=y_{m}+\rho(b)
$$

where $\rho(b)$ is the component of the external transfer that comes in the form of the modern good.

Labor is mobile between the two sectors, but we state labor market equilibrium in a manner that allows for structural misallocation in the economy. In particular, we assume there is a wedge of magnitude $\varphi>0$ that prevents the equalization of the value marginal products of labor in the two sectors. So:

$$
p \theta_{m} f^{\prime}\left(l_{m}\right)=\theta_{t} g^{\prime}\left(1-l_{m}\right)+\varphi
$$

Since the value of the marginal product of labor is higher in the modern sector than in the traditional sector in equilibrium, the economy has too few workers in the modern sector. Structural change in the direction of the modern sector - a movement of workers from the traditional to modern sector - would increase economywide labor productivity. 
This completes the description of the formal model. We have a system of eight independent equations that determines the following eight endogenous variables: $p, l_{m}, c_{m}, c_{t}, y_{m}, y_{t}, y$ and $z$. We will use this system to perform comparative statics on both demand-side $(b)$ and supply-side shocks $\left(\theta_{m}, \theta_{t}\right)$.

The equilibrium of the model can be pictured with the help of Figure 14. The horizontal axis represents the size of the labor force, with the two vertices as the origins of the modern and traditional sectors, respectively. The vertical axes measure the value marginal product of labor in the modern (left axis) and traditional (right axis) sectors $\left(V M P L_{m}\right.$ and $\left.V M P L_{t}\right)$. The downward sloping schedules, from the perspective of each origin, capture the declining physical marginal product of labor as employment increases, holding all else constant. The equilibrium allocation of labor is determined such that $V M P L_{m}$ exceeds $V M P L_{t}$ exactly by $\varphi$, the wedge between productivity in the two sectors. Note that the $V M P L_{m}$ schedule is drawn for the equilibrium value of the relative price $p$, which is determined with the addition of the demand-side of the system.

We begin by analyzing supply side shocks, setting $b=0$. Consider first a positive supply shock to the modern sector that leads the sector to expand on impact. In terms of the model, this corresponds to an increase in $\theta_{m}$. This shifts the $V M P L_{m}$ schedule up, as shown in Figure 15 . However, this cannot be the end of the story, since the increase in income that is generated in the modern sector has implications for relative prices. On impact, the supply shock raises the supply of modern goods, while leaving the supply of traditional goods unchanged. The resulting income gains will show up as increases in demand for both goods. Consequently, the impact effect of the shock is to create an excess supply of the modern good (and an excess demand for the traditional good). The relative price of the modern $\operatorname{good}(p)$ will therefore have to decline.

The magnitude of the decline depends on preferences. Given our assumption of price elastic demand for the modern good, the decline in $p$ has to be smaller in proportional terms than the increase in $\theta_{m}$. To see why, assume, counterfactually, that the decline was proportionally identical, so that the $V M P L_{m}$ schedule returned to its original, pre-shock position (i.e., that $\frac{d p}{p}=-\frac{d \theta_{m}}{\theta_{m}}$ ). Since the fall in $p$ exactly offsets the rise in $y_{m}$, there would be no income effect on the composition of expenditures (recall that $z=y=y_{t}+p y_{m}$ ). However, there would still be an excess demand for the modern good, because price elastic demand implies that the quantity demanded would have risen more than the 
supply. Hence to reinstate goods-market equilibrium $p$ must fall by less (so that $\left|\frac{d p}{p}\right|<\left|\frac{d \theta_{m}}{\theta_{m}}\right|$ ). Consequently, the $V M P L_{m}$ schedule shifts only partway back in the final equilibrium (see Figure 15). ${ }^{8}$

The result is that the positive supply shock to the modern sector ends up increasing both labor productivity $\left(\theta_{m} f^{\prime}\left(l_{m}\right)\right)$ and employment $\left(l_{m}\right)$ in the modern sector (Figure 15). Note further that any increase in total expenditures $z$ due to the positive productivity shock would reinforce this outcome, as it would lead to greater demand at the margin for the modern sector, and hence expanded employment there. As we discussed in the previous section, this is the canonical East Asian pattern of structural change during the process of economic development.

Next, consider a positive productivity shock in the traditional sector $\left(d \theta_{t}>0\right)$. This shifts the $V M P L_{t}$ schedule up (Figure 16). Once again, there will be a relative price adjustment. The excess supply of the traditional good will drive up the relative price of the modern sector, $p$. As regards the direction of change in the equilibrium allocation of labor, what matters is whether the rise in $p$ is proportionally larger or smaller than the increase in $\theta_{t}$. Our assumptions on preferences pull in conflicting directions in this case. The income effect produces a desired increase in the budget share of the modern good, which requires a proportionately larger increase in $p$. But the fact that the budget share of the modern good is decreasing in $p$ pushes in the opposite direction. We assume here that the income effect dominates (as in Matsuyama 1992), so that $\frac{d p}{p}>\frac{d \theta_{t}}{\theta_{t}}$.

In terms of our figure, this means there will be a commensurately greater upwards shift in the $V M P L_{m}$ schedule relative to the $V M P L_{t}$ schedule. The result, as shown in Figure 16., is once again an increase in employment in the modern sector, $l_{m}$. However, in this case expansion of the modern sector is accompanied by a decline in labor productivity in the modern sector $\left(\theta_{m} f^{\prime}\left(l_{m}\right)\right)$, because of the declining marginal productivity of labor (and the absence of any increase in $\theta_{m}$ ). This outcome is reminiscent of the African model of structural change we discussed previously.

There is reason to believe that developments in African agriculture in particular have been important in driving economic growth there. A large part of total employment (60-80\%) in low-income African counties remains in the agricultural sector. Even modest growth in agriculture can have a

\footnotetext{
${ }^{8}$ The general case, but with homothetic preferences is derived in a similar model in Dani Rodrik (2016). For the case of non-homothetic preferences, see Kiminori Matsuyama (1992). However, Matsuyama assumes the price elasticity of demand for manufacturing is unity, which implies that an increase in manufacturing productivity leaves manufacturing employment unchanged. Our assumption of price elastic demand for the modern good produces a different result, as explained in the text,
} 
significant demand effect in domestic markets for nonagricultural goods and services. Among the lowincome African countries in the GGDC dataset, total within sector labor productivity growth is mainly explained by agricultural productivity growth in 6 of the 8 countries, and agricultural productivity growth is important in three of the four countries in Group 1 (ETH, TZA and MWI). When income increases among the rural population and it is spent disproportionally on nonagricultural products, this creates a market for small businesses in the informal economy, including micro and small manufacturing firms that can provide import substitutes but at much lower prices (and often with lower quality). Such informal manufacturing operations often have low labor productivity. This explains why modern-sector labor productivity (including in manufacturing) falls with structural change.

Finally, we consider a positive demand-side shock to the economy, in the form an external transfer $b$. The relative-price implications of this would depend on the specific composition of the transfer in terms of the modern and traditional goods. We consider a neutral "aggregate demand" shock such that the transfer expands the supply of the two goods available to domestic consumers in equal proportions. Therefore, at the initial relative prices the expenditure shares of the two goods remain unchanged.

However, since consumers are now richer, their desired budget share of the modern good increases. This implies that the relative price of the modern sector $p$ must rise. This shifts the $V M P L_{m}$ schedule up and induces an increase in modern-sector employment. The equilibrium is as shown in Figure 17. In the new equilibrium, labor productivity in the modern sector falls as employment expands. This demand-driven pattern of structural change is also in line with the African model.

The shocks that generate Asian versus African patterns of structural change have differing implications for relative prices as well, as sketched out above. A positive supply-side shock in the modern sector reduces the relative price of the modern sector, while a positive aggregate demand shock or a productivity shock in the traditional sector raises it. When structural change is driven from the demand-side or by productivity increase in the traditional sector, expanding modern sectors will also experience a rise in their relative prices. As Table 7 shows, this is broadly consistent with the African experience for countries in Group 1 - those that experienced strong structural change with declining within-sector labor productivity in modern sectors.

We also compare the domestic relative prices of manufacturing (the archetypal modern sector) in the Asian and African countries during their high-growth periods. As Figure 18 shows, manufacturing 
prices in Asia exhibit a very sharp drop relative to economywide prices, especially during the highgrowth years of the 1960 s and 1970s. The decline is by a factor of 2-4 over a period of three decades. In Africa, by contrast, there is either a much smaller decline, or no downward trend at all (Figure 19). During the growth acceleration years, African countries exhibit no fall in manufacturing relative prices. This is consistent with the expansion in African manufacturing (such as it is) being driven mostly by the demand effects of developments originating elsewhere in the economy.

\section{Concluding Remarks: The Sustainability of Recent Growth Accelerations}

A large number of countries in Latin America and Sub-Saharan Africa have experienced growth accelerations beginning in the early 1990s, making the most recent couple of decades a rare period of economic convergence with advanced economies. Yet we know from the history of growth spurts in the developing world that many growth accelerations eventually peter out (Pritchett, Hausmann and Rodrik 2005; Jones and Olken 2008). The present sample includes four countries where, after the initial acceleration, annual labor productivity growth fell below 1 percent (Mexico, Malawi, Senegal and South Africa) and one country where it turned negative (Venezuela). By contrast, growth accelerated early and lasted for three to four decades in Botswana, Ghana, India, and Mauritius (see Table 3). The latter countries' longer term growth patterns could help us better understand the potential paths of other countries in Africa and Latin America.

We present in Figure 20 the long term growth patterns in each decade following these four countries' growth take-offs. Their growth accelerations were triggered by different mechanisms: diamond discoveries in Botswana in the mid-1960s; the creation of an export processing zone and the emergence of a labor-intensive manufacturing sector in Mauritius during the early 1970s; and businessand market-friendly reforms that unleashed private sector investment in Ghana and India during the 1980s. Because of these different initial triggers, we are likely to find different patterns of growth across these four countries.

We summarize the salient features of each country's experience in Table 8 paying particular attention to the roles of within-sector labor productivity growth and structural change. One thing that Table 8 makes clear is the importance of robust within sector productivity growth. In all four countries, within sector labor productivity growth makes a positive contribution to labor productivity growth in the early years and becomes increasingly important as time goes on. By contrast, structural change plays an important role in the early years and becomes less important over time. This is as expected: we pointed 
out in section 2 the diminishing importance of inter-sectoral labor reallocation over the course of development, as structural productivity gaps diminish.

In addition, we can see from Table 8 that the manufacturing sector has not always contributed a significant growth impetus. Mauritius followed the East Asian path and industrialization figured prominently in economywide labor productivity growth, especially during the first two decades when structural change also played an important role. The share of manufacturing employment peaked at more than 30 percent of total employment in the late 1980s. Botswana, on the other hand, never established a sizable manufacturing sector. In Ghana, manufacturing contributed to within-sector labor productivity growth and exhibited modest increases in employment in the early years of the country's growth acceleration. But in subsequent periods manufacturing's employment share has remained stagnant. Ghana's labor productivity growth has been balanced across sectors making it difficult to identify a leading sector.

As in Ghana, the share of manufacturing employment in India has stagnated at around 12 percent. Manufacturing did contribute to labor productivity growth through structural change, although within-sector labor productivity growth has been the main driver of growth in India. Over a period of nearly thirty years, India's manufacturing employment share increased by a mere 2 percentage points. Overall labor productivity growth in India was modest during the first decade of the growth acceleration, but it accelerated in the following decades. Meanwhile, agriculture's share of employment fell by 16 percentage points, as employment in service sectors grew. In terms of broad patterns of structural change, Ghana and India are quite similar, although India has experienced much higher within-sector labor productivity growth in recent years.

The growth experiences that raise the greatest concern with respect to sustainability are those that exhibit stagnant or declining within-sector labor productivity in the modern sectors, as in many of our African cases. As the experience with sustained growth we have just summarized indicates, productivity growth in the modern sectors is the sine qua non of longer-term development.

This is not to belittle the significance of rapid productivity growth in agriculture, the archetypal traditional sector. Our model suggests agriculture has played a key role in Africa not only on its own account, but also as a driver of growth-increasing structural change. Diversification into non-traditional products and adoption of new production techniques can transform agriculture into a modern activity in part. But there are limits to how far this process can carry the economy. In part because of the low 
income elasticity of demand for agricultural products, a movement of labor out of agriculture is an inevitable outcome during the process of development. The labor that is released has to be absorbed in modern activities. And if productivity is not growing in these modern sectors, economywide growth ultimately will stall. This is so on account of both the within and structural-change components. The contribution that the structural-change component can make is necessarily self-limiting if the modern sector does not experience rapid productivity growth on its own.

It is possible of course that the increase in demand for modern-sector goods would lead to capital accumulation and technology adoption in modern services, setting off a process of productivity growth. Perhaps this will eventually happen in Africa. But it does not show up in the data so far.

None of this is to suggest that low-income African countries cannot sustain moderate rates of productivity growth, on the back of steady improvements in human capital and governance. In view of the prospects for advanced economies, continued convergence seems quite achievable. But the recent exceptional growth rates engineered with the help of rapid growth-promoting structural change may well be out of reach. 


\section{References}

Aghion, P., and P. Howitt 1992. "A Model of Growth through Creative Destruction." Econometrica 60(2): 323-51.

de Vries, G. J, M. P. Timmer, and K. de Vries. 2015. "Structural Transformation in Africa: Static Gains, Dynamic Losses." The Journal of Development Studies 51(6): 674-88.

Diao, X., K. Harttgen, and M. McMillan. 2017. The Changing Structure of Africa's Economies. NBER Working Paper 23021. Cambridge, MA: National Bureau of Economic Research; World Bank Economic Review, forthcoming.

Duarte, M., and D. Restuccia. 2010. "The Role of the Structural Transformation in Aggregate Productivity." Quarterly Journal of Economics 125 (1): 129-73.

Gollin, D., D. Lagakos, and M. E. Waugh. 2014. "The Agricultural Productivity Gap." Quarterly Journal of Economics 129 (2): 939-93.

Grossman, G.M., and E. Helpman 1991. Innovation and Growth in the Global Economy. Cambridge, MA: The MIT Press.

Hausmann, R. L. Pritchett, and D. Rodrik. 2005. "Growth Accelerations." Journal of Economic Growth 10(4): 303-29.

Jones, B.F., and B.A. Olken. 2008. "The Anatomy of Start-Stop Growth." Review of Economics and Statistics 90(3): 582-87.

Klasen, S., and D. Blades. 2013. Special Issue: Measuring Income, Wealth, Inequality, and Poverty in Sub Saharan Africa: Challenges, Issues, and Findings. Review of Income and Wealth 59 (s1): S1-S200.

Kuznets, S. 1955. "Economic Growth and Income Inequality." American Economic Review 45 (March): 128.

Lewis, A. W. 1954. "Economic Development with Unlimited Supplies of Labor." The Manchester School 22: 139-91.

McCullough, E.B., 2015. Labor Productivity and Employment Gaps in Sub-Saharan Africa. World Bank Policy Research Working Paper 7234. Washington DC: World Bank.

McMillan, M., D. Rodrik, and C. Sepulveda. 2017. Structural Change, Fundamentals, and Growth: A Framework and Country Studies Washington DC: International Food Policy Research Institute (forthcoming).

McMillan, M., and D. Rodrik. 2011. Globalization, Structural Change, and Productivity Growth. NBER Working Paper 17143. Cambridge, MA: National Bureau of Economic Research.

Mundlak, Y., R. Butzer, and D. F. Larson. 2012. "Heterogeneous Technology and Panel Data: The Case of the Agricultural Production Function." Journal of Development Economics 99(1): 139-49. 
Matsuyama, K. 1992. "Agricultural Productivity, Comparative Advantage, and Economic Growth." Journal of Economic Theory 58: 317-34.

Rodrik, D. 2016. "Premature Deindustrialization." Journal of Economic Growth March; 21(1): 1-33.

Rodrik, D. 2014. "The past, present, and future of economic growth." In Franklin Allen and others, Towards a Better Global Economy: Policy Implications for Citizens Worldwide in the 21st Century. Oxford and New York: Oxford University Press, 2014.

Solow, R.M. 1956. "A Contribution to the Theory of Economic Growth." The Quarterly Journal of Economics 70(1): 65-94.

Timmer, M. P., and G. J. de Vries. 2007. A Cross-Country Database for Sectoral Employment and Productivity in Asia and Latin America, 1950-2005. Gronigen Growth and Development Centre Research Memorandum 98. Gronigen, Netherlands: University of Gronigen.

- - . 2009. "Structural Change and Growth Accelerations in Asia and Latin America: A New Sectoral Data Set." Cliometrica 3 (2): 165-90.

Timmer, M. P., G. J. de Vries, and K. de Vries. 2015. Patterns of Structural Change in Developing Countries. In J. Weiss, \& M. Tribe (Eds.), Routledge Handbook of Industry and Development. (pp. 65-83). Routledge.

Wei, S., and X. Zhang, 2011. Sex Ratios, Entrepreneurship and Economic Growth in the People's Republic of China. NBER Working Paper 16800. Cambridge, MA: National Bureau of Economic Research.

World Bank. 2016. World Development Indicators. Download of dataset from http://databank.worldbank.org/data/reports.aspx?source=world-development-indicators. Accessed on January 6, 2017. 
Table 1. Summary Statistics

\begin{tabular}{|c|c|c|c|c|c|c|c|c|}
\hline & \multirow[b]{2}{*}{ Code } & \multirow[b]{2}{*}{$\begin{array}{c}\text { Economywide } \\
\text { labor } \\
\text { productivity }\end{array}$} & \multirow[b]{2}{*}{$\begin{array}{l}\text { Coef. of } \\
\text { variation of } \\
\text { log of } \\
\text { sectoral } \\
\text { productivity }\end{array}$} & \multicolumn{2}{|c|}{ Sector with highest labor productivity } & \multicolumn{2}{|c|}{$\begin{array}{c}\text { Sector with lowest labor } \\
\text { productivity }\end{array}$} & \multirow[b]{2}{*}{$\begin{array}{c}\text { Annual } \\
\text { growth rate of } \\
\text { economywide } \\
\text { productivity } \\
(\%)\end{array}$} \\
\hline & & & & Sector & $\begin{array}{l}\text { Labor } \\
\text { productivity }\end{array}$ & Sector & $\begin{array}{l}\text { Labor } \\
\text { productivity }\end{array}$ & \\
\hline \multicolumn{9}{|l|}{ High Income } \\
\hline United States & USA & 83.2 & 0.065 & Utilities & 367.0 & Personal services & 52.3 & 1.68 \\
\hline Netherlands & NLD & 53.1 & 0.108 & Mining & 1745.8 & Personal services & 28.5 & 1.41 \\
\hline United Kingdom & GBR & 52.9 & 0.086 & Mining & 603.3 & Agriculture & 26.5 & 1.59 \\
\hline Japan & JPN & 52.2 & 0.061 & Utilities & 197.9 & Agriculture & 16.1 & 1.17 \\
\hline France & FRA & 49.2 & 0.047 & Utilities & 157.4 & Business services & 20.7 & 1.01 \\
\hline Sweden & SWE & 47.2 & 0.060 & Utilities & 223.0 & Business services & 31.6 & 3.44 \\
\hline Italy & ITA & 45.2 & 0.094 & Utilities & 220.0 & Business services & 5.2 & -0.79 \\
\hline Denmark & DNK & 44.8 & 0.118 & Mining & 1787.5 & Business services & 17.9 & 0.28 \\
\hline Spain & ESP & 41.8 & 0.063 & Utilities & 222.4 & Business services & 16.7 & 0.30 \\
\hline \multicolumn{9}{|l|}{ Asia } \\
\hline Singapore & SGP & 81.3 & 0.090 & Utilities & 274.9 & Agriculture & 13.4 & -0.35 \\
\hline Hong Kong & HKG & 64.3 & 0.084 & Utilities & 465.6 & Agriculture & 20.2 & 3.57 \\
\hline Taiwan & TWN & 52.0 & 0.092 & Mining & 473.6 & Construction & 17.0 & 1.29 \\
\hline South Korea & KOR & 37.7 & 0.085 & Utilities & 304.0 & Agriculture & 18.0 & 2.38 \\
\hline Malaysia & MYS & 29.2 & 0.125 & Mining & 1063.5 & Construction & 10.7 & 2.75 \\
\hline Thailand & THA & 11.8 & 0.155 & Mining & 305.5 & Agriculture & 2.7 & 2.77 \\
\hline Philippines & $\mathrm{PHL}$ & 7.8 & 0.115 & Utilities & 79.7 & Personal services & 2.5 & 2.51 \\
\hline China & $\mathrm{CHN}$ & 7.4 & 0.127 & Utilities & 48.1 & Personal services & 1.4 & 10.38 \\
\hline Indonesia & IDN & 7.0 & 0.118 & Mining & 102.6 & Agriculture & 2.3 & 2.66 \\
\hline India & IND & 5.1 & 0.107 & Utilities & 40.7 & Agriculture & 1.7 & 6.38 \\
\hline \multicolumn{9}{|l|}{ Latin America } \\
\hline Brazil & BRA & 78.2 & 0.100 & Utilities & 774.6 & Personal services & 25.0 & 0.88 \\
\hline Chile & $\mathrm{CHL}$ & 28.5 & 0.094 & Mining & 281.5 & Agriculture & 13.1 & 1.85 \\
\hline Venezuela & VEN & 25.9 & 0.114 & Mining & 421.3 & Agriculture & 10.5 & -0.34 \\
\hline Mexico & MEX & 25.1 & 0.119 & Mining & 422.2 & Agriculture & 6.2 & -0.51 \\
\hline Argentina & ARG & 23.5 & 0.100 & Mining & 326.3 & Personal services & 9.3 & 1.75 \\
\hline Costa Rica & CRI & 20.5 & 0.029 & Transport services & 31.2 & Agriculture & 12.5 & 1.77 \\
\hline Colombia & $\mathrm{COL}$ & 14.1 & 0.111 & Utilities & 232.8 & Agriculture & 6.1 & 1.27 \\
\hline Peru & PER & 13.7 & 0.107 & Mining & 110.7 & Agriculture & 3.8 & 3.73 \\
\hline Bolivia & $\mathrm{BOL}$ & 7.5 & 0.126 & Utilities & 71.8 & Construction & 2.8 & 0.77 \\
\hline \multicolumn{9}{|l|}{ Africa } \\
\hline Botswana & BWA & 29.9 & 0.126 & Mining & 418.8 & Agriculture & 1.9 & 2.68 \\
\hline South Africa & $\mathrm{ZAF}$ & 23.9 & 0.091 & Utilities & 96.8 & Agriculture & 4.3 & 2.57 \\
\hline Mauritius & MUS & 22.1 & 0.061 & Utilities & 83.0 & Personal services & 12.3 & 2.87 \\
\hline Nigeria & NGA & 5.0 & 0.243 & Mining & 1549.5 & Personal services & 0.8 & 3.81 \\
\hline Ghana & GHA & 4.6 & 0.091 & Utilities & 23.6 & Trade services & 2.6 & 2.59 \\
\hline Senegal & SEN & 4.0 & 0.161 & Utilities & 129.8 & Agriculture & 1.3 & 1.24 \\
\hline Kenya & KEN & 3.1 & 0.114 & Utilities & 32.7 & Agriculture & 1.6 & 1.09 \\
\hline Zambia & ZMB & 2.7 & 0.173 & Utilities & 36.3 & Personal services & 0.3 & 3.00 \\
\hline Tanzania & TZA & 2.5 & 0.163 & Business services & 83.0 & Personal services & 0.5 & 4.37 \\
\hline Malawi & MWI & 2.2 & 0.124 & Mining & 46.4 & Agriculture & 1.0 & 2.23 \\
\hline Ethiopia & ETH & 1.4 & 0.148 & Mining & 31.2 & Agriculture & 0.8 & 5.07 \\
\hline
\end{tabular}

Note: All data used in this table come from GGDC. All productivity numbers are for average 2000-2010 and are in 2005 purchasing powering parity (PPP) $\$ 1,000$.

Source: Diao, Harttgen and McMillan 2017. 
Table 2. Sector Coverage and Labor Productivity ('000 of 2000 PPP USD)

\begin{tabular}{|c|c|c|c|c|c|}
\hline \multirow[b]{2}{*}{ Sector } & \multirow[b]{2}{*}{$\begin{array}{l}\text { Average sector } \\
\text { labor productivity }\end{array}$} & \multicolumn{2}{|c|}{$\begin{array}{l}\text { Maximum sector labor } \\
\text { productivity }\end{array}$} & \multicolumn{2}{|c|}{$\begin{array}{l}\text { Minimum sector labor } \\
\text { productivity }\end{array}$} \\
\hline & & Country & $\begin{array}{c}\text { Labor } \\
\text { productivity }\end{array}$ & Country & $\begin{array}{c}\text { Labor } \\
\text { productivity }\end{array}$ \\
\hline Agriculture & 14.9 & United States & 53.7 & Ethiopia & 0.66 \\
\hline Mining & 311.2 & Denmark & $1,787.5$ & Ethiopia & 2.27 \\
\hline Manufacturing & 40.4 & Brazil & 121.9 & Ethiopia & 1.72 \\
\hline Utilities & 155.5 & Brazil & 774.6 & Nigeria & 2.61 \\
\hline Construction & 26.7 & United States & 69.5 & Malawi & 3.64 \\
\hline Trade services & 25.7 & Singapore & 95.0 & Ethiopia & 2.59 \\
\hline Transport services & 43.6 & Brazil & 138.9 & Nigeria & 2.54 \\
\hline Business services & 42.8 & United States & 154.2 & Nigeria & 6.69 \\
\hline Government services & 24.4 & Brazil & 126.0 & Nigeria & 1.32 \\
\hline Personal services & 23.9 & Hong Kong & 114.5 & Tanzania & 0.33 \\
\hline Total economy & 30.0 & United States & 83.2 & Ethiopia & 1.37 \\
\hline
\end{tabular}


Table 3. Episodes of Rapid Growth and Magnitude of Accelerations (Annual Average Growth Rate)

\begin{tabular}{|c|c|c|c|c|c|c|}
\hline Country & $\begin{array}{l}\text { Initial year } \\
\text { of growth } \\
\text { acceleration } \\
\text { (t) }\end{array}$ & $\begin{array}{l}\text { growth in } \\
\text { pre-accel'n } \\
\text { period } \\
(\mathrm{t}-6, \mathrm{t})\end{array}$ & $\begin{array}{c}\text { growth in } \\
\text { post-accel'n } \\
\text { period } \\
(t, t+6)\end{array}$ & $\begin{array}{c}\text { Differences } \\
\text { in pre- \& } \\
\text { post-accel'n } \\
\text { periods }\end{array}$ & $\begin{array}{c}\text { Whether GDP pc in } \\
\text { post-accel'n } \\
\text { period >= max in pre- } \\
\text { accel'n } \\
\text { period }\end{array}$ & $\begin{array}{l}\text { Growth after } \\
7 \text {-years' } \\
\text { growth } \\
\text { acceleration } \\
(\mathrm{t}+6,2014) \\
\end{array}$ \\
\hline ARG & 1992 & -0.54 & 2.80 & 3.34 & Yes & 2.98 \\
\hline BRA & 2002 & 0.50 & 3.00 & 2.50 & Yes & 2.90 \\
\hline $\mathrm{CHL}$ & 1988 & 2.66 & 6.25 & 3.59 & Yes & 3.02 \\
\hline $\mathrm{COL}$ & 2001 & -0.79 & 3.66 & 4.45 & Exceeded in 2003/04 & 3.19 \\
\hline MEX & 1996 & -0.12 & 2.28 & 2.40 & Exceeded in $1997 / 98$ & 0.92 \\
\hline PER & 2002 & 0.76 & 5.47 & 4.71 & Yes & 4.17 \\
\hline VEN & 2001 & -1.11 & 4.20 & 5.31 & Exceeded in 2005/06 & -0.18 \\
\hline $\mathrm{BOL}$ & 2003 & 0.34 & 2.93 & 2.59 & Yes & 3.77 \\
\hline CRI & 2002 & 2.59 & 4.76 & 2.17 & Yes & 3.23 \\
\hline BWA & 1967 & 3.33 & 13.35 & 10.03 & Yes & 4.74 \\
\hline ETH & 2000 & 1.13 & 3.71 & 2.59 & Yes & 7.95 \\
\hline GHA & 1984 & -5.23 & 2.02 & 7.25 & Exceeded in 1999 & 2.85 \\
\hline KEN & 2003 & -0.34 & 2.08 & 2.42 & Exceeded in 2004 & 3.04 \\
\hline MWI & 2002 & -1.51 & 3.60 & 5.11 & Exceeded in 2006 & 0.35 \\
\hline MUS & 1973 & 1.14 & 6.31 & 5.17 & Yes & 4.10 \\
\hline NGA & 2000 & 0.30 & 7.61 & 7.31 & Yes & 3.21 \\
\hline SEN & 1995 & -1.65 & 2.23 & 3.88 & Exceeded in 1999 & 0.98 \\
\hline ZAF & 2001 & 0.98 & 3.10 & 2.12 & Yes & 0.83 \\
\hline TZA & 1998 & 0.67 & 3.50 & 2.83 & Yes & 3.13 \\
\hline $\mathrm{ZMB}$ & 2000 & 0.64 & 3.77 & 3.13 & Yes & 4.60 \\
\hline IND & 1983 & 1.52 & 3.59 & 2.07 & Yes & 4.93 \\
\hline
\end{tabular}

Note: Based on the method in Hausmann, Pritchett and Rodrik (2005)

Source: Authors' calculations using data of PWT (9.0). http://www.rug.nl/ggdc/productivity/pwt/ 
Table 4. The Annual Growth Rates for Per Capita GDP and Labor Productivity

\begin{tabular}{|c|c|c|c|c|c|c|c|c|c|c|}
\hline \multirow[t]{2}{*}{ Country } & \multirow{2}{*}{$\begin{array}{l}\text { Initial year } \\
\text { of growth } \\
\text { acceleration } \\
\text { (t) }\end{array}$} & \multicolumn{3}{|c|}{$\begin{array}{l}\text { Seven years in pre- } \\
\text { growth accel'n period } \\
(\mathrm{t}-6, \mathrm{t})\end{array}$} & \multicolumn{3}{|c|}{$\begin{array}{l}\text { Seven years in post-growth } \\
\text { accel'n period }(t, t+6)\end{array}$} & \multicolumn{3}{|c|}{$\begin{array}{l}\text { Differences in pre and post } \\
\text { growth accel'n periods }\end{array}$} \\
\hline & & PWT & WDI & GGDC & PWT & WDI & GGDC & PWT & WDI & GGDC \\
\hline ARG & 1992 & -0.54 & -0.45 & -1.33 & 2.80 & 2.76 & 3.40 & 3.34 & 3.22 & 4.73 \\
\hline BRA & 2002 & 0.50 & 0.48 & -0.12 & 3.00 & 3.04 & 1.18 & 2.50 & 2.56 & 1.30 \\
\hline $\mathrm{CHL}$ & 1988 & 2.66 & 3.99 & -0.74 & 6.25 & 6.25 & 4.12 & 3.59 & 2.25 & 4.87 \\
\hline $\mathrm{COL}$ & 2001 & -0.79 & -0.53 & -1.19 & 3.66 & 3.66 & 1.30 & 4.45 & 4.20 & 2.48 \\
\hline MEX & 1996 & -0.12 & 0.53 & -0.77 & 2.28 & 1.57 & -0.24 & 2.40 & 1.04 & 0.53 \\
\hline PER & 2002 & 0.76 & 0.76 & -0.97 & 5.47 & 5.47 & 4.47 & 4.71 & 4.71 & 5.44 \\
\hline VEN & 2001 & -1.11 & -1.11 & -1.19 & 4.20 & 4.20 & 0.48 & 5.31 & 5.31 & 1.67 \\
\hline BOL & 2003 & 0.34 & 0.34 & -0.14 & 2.93 & 2.93 & 1.55 & 2.59 & 2.59 & 1.69 \\
\hline CRI & 2002 & 2.59 & 2.59 & 1.19 & 4.76 & 4.76 & 2.44 & 2.17 & 2.17 & 1.25 \\
\hline BWA & 1967 & 3.33 & 3.41 & 0.00 & 13.35 & 16.11 & 11.62 & 10.03 & 12.71 & 11.62 \\
\hline ETH & 2000 & 1.13 & 1.15 & 0.58 & 3.71 & 3.71 & 3.33 & 2.59 & 2.57 & 2.74 \\
\hline GHA & 1984 & -5.23 & -5.23 & -5.34 & 2.02 & 2.02 & 3.47 & 7.25 & 7.25 & 8.80 \\
\hline KEN & 2003 & -0.34 & -0.43 & -0.94 & 2.08 & 2.11 & 1.44 & 2.42 & 2.54 & 2.37 \\
\hline MWI & 2002 & -1.51 & -1.43 & 0.39 & 3.60 & 2.93 & 2.52 & 5.11 & 4.36 & 2.14 \\
\hline MUS & 1973 & 1.14 & N.A. & N.A. & 6.31 & N.A. & 7.84 & 5.17 & N.A. & N.A. \\
\hline NGA & 2000 & 0.30 & 0.14 & -0.27 & 7.61 & 8.71 & 6.06 & 7.31 & 8.57 & 6.33 \\
\hline SEN & 1995 & -1.65 & -1.50 & -0.68 & 2.23 & 1.89 & 1.77 & 3.88 & 3.39 & 2.45 \\
\hline ZAF & 2001 & 0.98 & 0.22 & 1.83 & 3.10 & 3.23 & 2.56 & 2.12 & 3.01 & 0.73 \\
\hline TZA & 1998 & 0.67 & 0.26 & 0.53 & 3.50 & 3.49 & 3.88 & 2.83 & 3.24 & 3.35 \\
\hline ZMB & 2000 & 0.64 & 0.64 & 0.23 & 3.77 & 3.77 & 1.83 & 3.13 & 3.13 & 1.59 \\
\hline IND & 1983 & 1.52 & 1.35 & 0.95 & 3.59 & 3.26 & 2.87 & 2.07 & 1.91 & 1.92 \\
\hline
\end{tabular}

Sources: Authors' calculations using data of PWT (9.0), WDI (World Bank 2017) and GGDC (2014). Accessed at http://www.rug.nl/research/ggdc/data/africa-sector-database 
Table 5. Number of Nonagricultural Sectors Contributing to Structural Change With and Without Labor Productivity Growth Within Sector (Group 1 Countries Only)

\begin{tabular}{|c|c|c|c|c|c|}
\hline & $\begin{array}{c}\text { Total SC led } \\
\text { growth, } \\
\text { (percentage points) }\end{array}$ & $\begin{array}{l}\text { \# of sectors with } \\
\text { positive SC but } \\
\text { negative within } \\
\text { sector } \\
\text { SC-1 }\end{array}$ & $\begin{array}{l}\text { \# of sectors with } \\
\text { positive SC \& } \\
\text { positive within } \\
\text { sector } \\
\text { SC-2 }\end{array}$ & $\begin{array}{l}\text { Manufacturing is in } \\
\text { SC- } 1 \text { \& its growth } \\
\text { contribution } \\
\text { (within sector vs. SC, } \\
\text { percentage point) }\end{array}$ & $\begin{array}{l}\text { Manufacturing is in } \\
\text { SC-2 \& its growth } \\
\text { contribution } \\
\text { (within sector vs. SC, } \\
\text { percentage point) }\end{array}$ \\
\hline MWI & 3.93 & 5 & 1 & $(-0.23,0.77)$ & \\
\hline TZA & 3.47 & 4 & 2 & & $(0.02,0.44)$ \\
\hline ETH & 2.25 & 4 & 1 & $(-0.17,0.36)$ & \\
\hline SEN & 1.80 & 4 & 2 & $(-0.39,0.54)$ & \\
\hline
\end{tabular}

Source: Authors' calculations using GGDC data 
Table 6. Correlation across African Countries by Nonagricultural Sector

\begin{tabular}{lrrr}
\hline & All countries & Group 1 countries & Group 2 countries \\
\hline Manufacturing & -0.875 & -0.378 & -0.726 \\
Construction & -0.361 & -0.747 & 0.589 \\
Trade services & -0.882 & -0.608 & -0.759 \\
Business services & -0.570 & -0.992 & 0.695 \\
Transport services & -0.814 & -0.823 & 0.176 \\
\hline
\end{tabular}

Source: Authors' calculations using GGDC data

Table 7. Correlation between Changes in Relative Sector Prices and Shares of Sectoral Value Added

\begin{tabular}{lrrr}
\hline & Group 1 & Group 2 & All countries \\
\hline With manufacturing & 0.325 & 0.080 & 0.185 \\
Without manufacturing & 0.294 & 0.084 & 0.168 \\
\hline
\end{tabular}

Source: Authors' calculations using GGDC data 
Table 8. Summary of Three Early-Growth African Countries Plus India

\begin{tabular}{|c|c|c|c|c|}
\hline & Botswana & Mauritius & Ghana & India \\
\hline $\begin{array}{l}\text { Per capita GDP growth rate in } 7 \\
\text { years prior to growth } \\
\text { acceleration }\end{array}$ & 3.33 & 1.14 & -5.23 & 1.52 \\
\hline $\begin{array}{l}\text { Triggers of growth } \\
\text { accelerations }\end{array}$ & $\begin{array}{l}\text { Discovery of } \\
\text { diamonds }\end{array}$ & $\begin{array}{l}\text { Development } \\
\text { of labor- } \\
\text { intensive } \\
\text { manufacturing }\end{array}$ & $\begin{array}{l}\text { Reforms } \\
\text { associated } \\
\text { with crisis }\end{array}$ & $\begin{array}{l}\text { Reforms out } \\
\text { of stagnant } \\
\text { growth }\end{array}$ \\
\hline $\begin{array}{l}\text { The most important sectors } \\
\text { contributing to growth } \\
\text { accelerations in the early years }\end{array}$ & $\begin{array}{l}\text { Mining, } \\
\text { construction, } \\
\text { private and } \\
\text { public services }\end{array}$ & $\begin{array}{c}\text { Manufacturing } \\
\text { and public } \\
\text { services }\end{array}$ & $\begin{array}{l}\text { Hard to } \\
\text { identify }\end{array}$ & $\begin{array}{l}\text { Hard to } \\
\text { identify }\end{array}$ \\
\hline $\begin{array}{l}\text { Impact of structural change in } \\
\text { the early years post-growth } \\
\text { accelerations }\end{array}$ & + and strong & + & + & + \\
\hline $\begin{array}{l}\text { Impact of structural change in } \\
\text { the later years post-growth } \\
\text { accelerations }\end{array}$ & - & $\begin{array}{l}+ \text { but smaller } \\
\text { than the early } \\
\text { years }\end{array}$ & $\begin{array}{c}\text { + and similar } \\
\text { to the early } \\
\text { years }\end{array}$ & $\begin{array}{l}+ \text { but smaller } \\
\text { than the early } \\
\text { years }\end{array}$ \\
\hline $\begin{array}{l}\text { Impact of labor productivity } \\
\text { growth within sector in the } \\
\text { early years after growth } \\
\text { accelerations }\end{array}$ & + and strong & + and strong & + and strong & $\begin{array}{c}+ \text { and similar } \\
\text { to structural } \\
\text { change }\end{array}$ \\
\hline $\begin{array}{l}\text { Impact of labor productivity } \\
\text { growth within sector in later } \\
\text { years }\end{array}$ & + and strong & + and strong & + and strong & + and strong \\
\hline
\end{tabular}

Source: Based on authors' calculations/assessment using GGDC data 
Figure 1. Labor Productivity Gaps in Africa, 2010

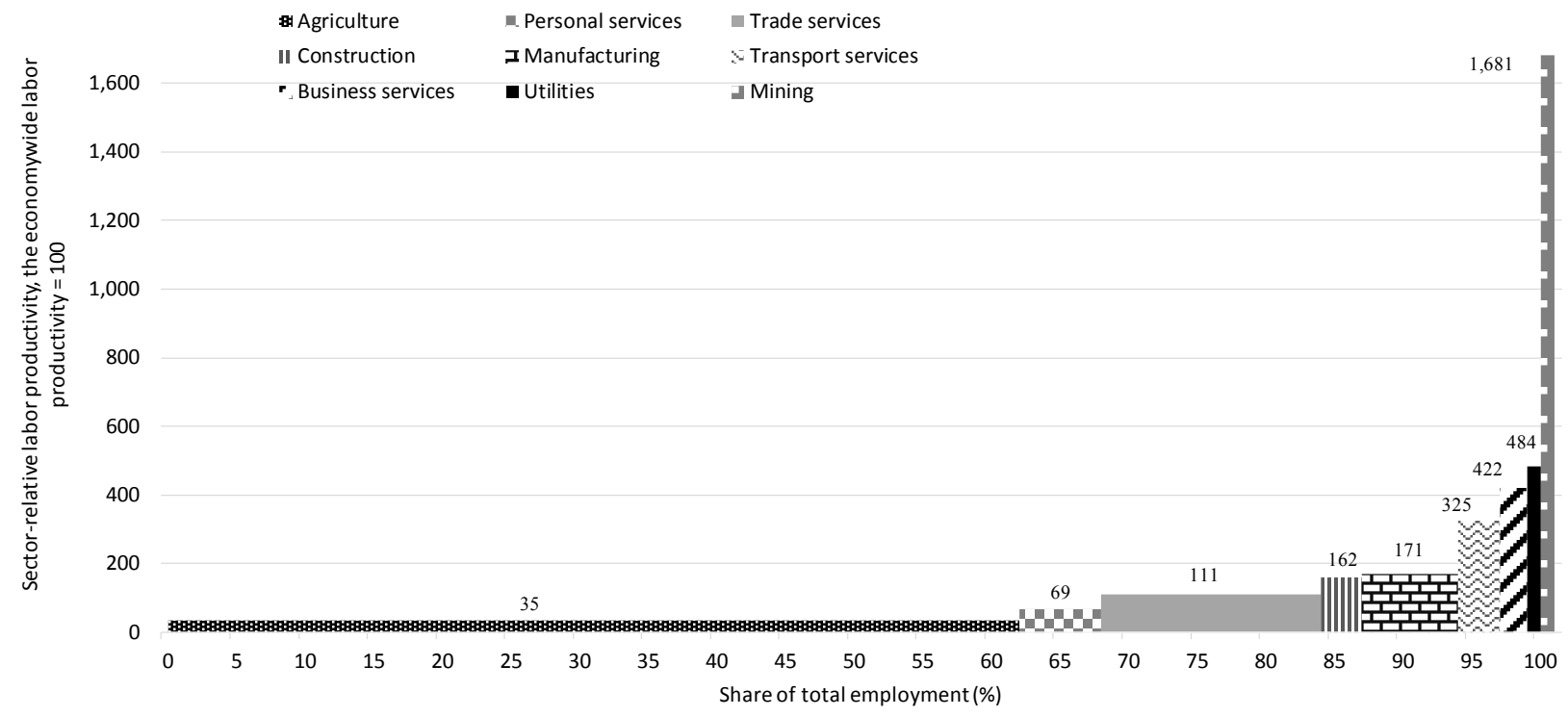

Note: The sector-relative labor productivity and sector share of employment are calculated using the weighted average for the region; the country data is in 2005 purchasing power parity (PPP) dollars.

Source: Diao, Harttgen and McMillan 2017. 
Figure 2: Sectoral Gaps in Labor Productivity Shrink as Income Rises

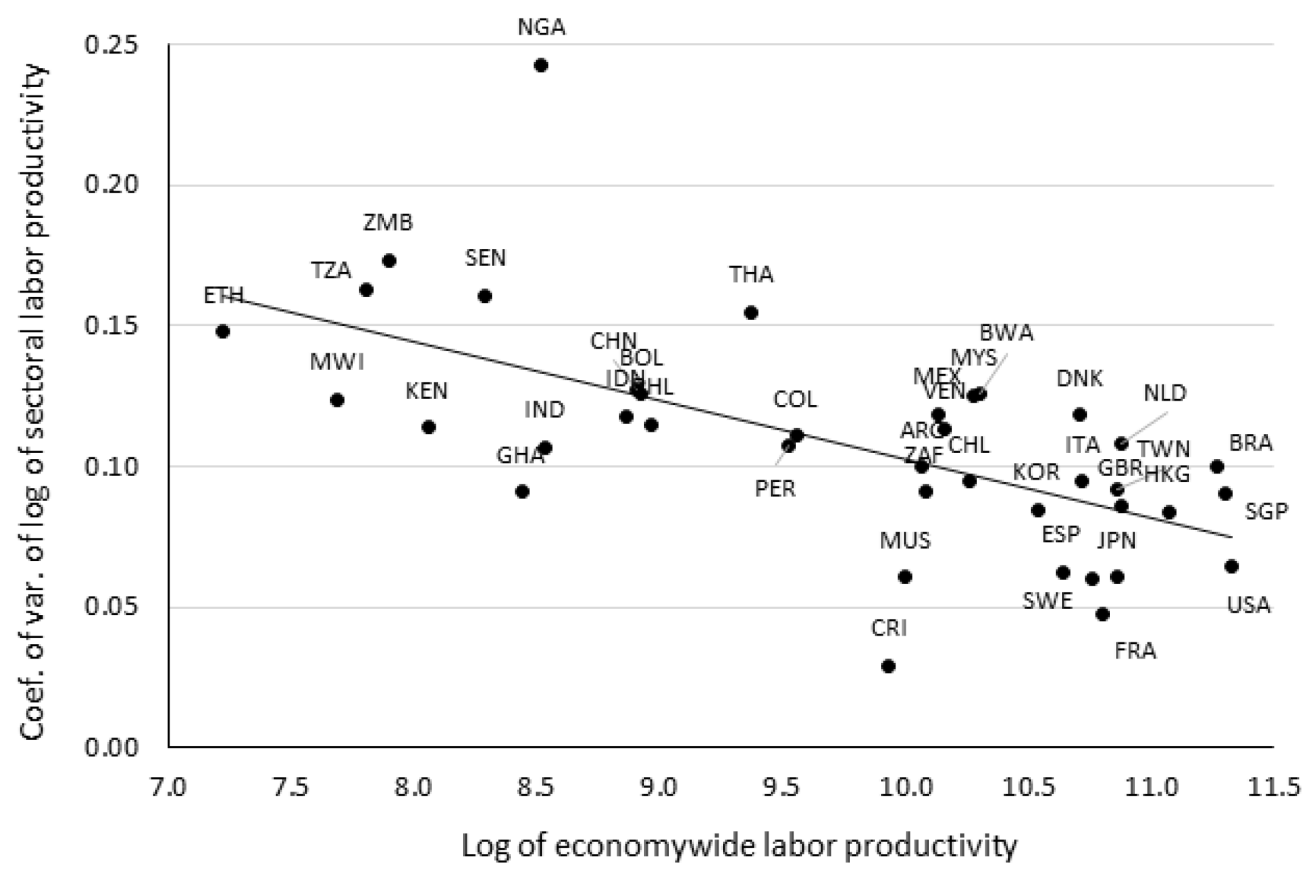

Note: Both economywide and sectoral labor productivity is value-added at 2005 purchasing power parity (PPP) dollar divided by total or sectoral employment and it is 2000-2010 average

Source: Authors' calculations using GGDC data. 
Figure 3. Level of Economywide Labor Productivity versus Ratio of Agricultural and Nonagricultural Productivity: China and India

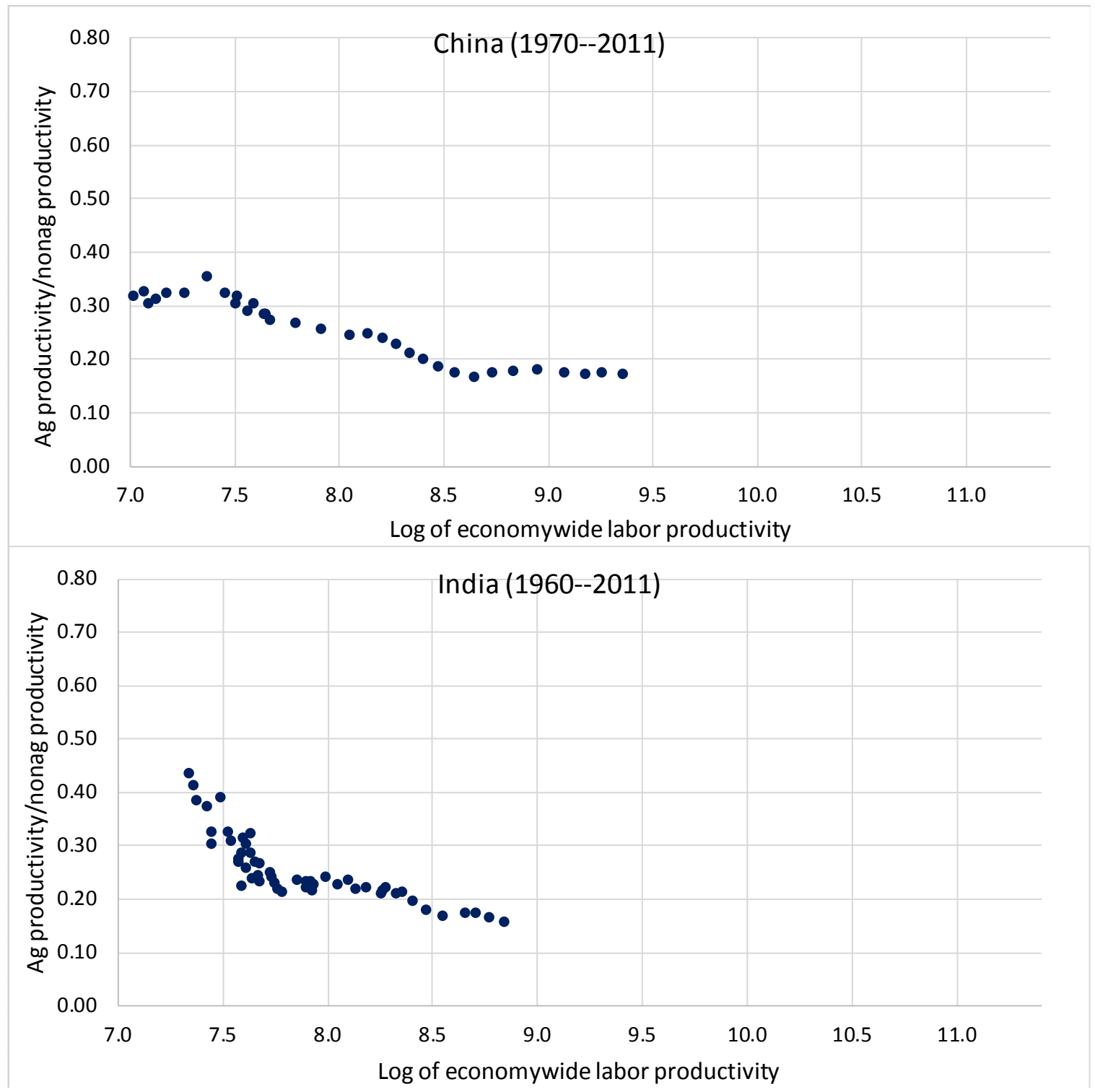

Note: Economywide labor productivity is total value-added at 2005 purchasing power parity (PPP) dollar divided by total employment. Agricultural and nonagricultural labor productivity is sectoral value-added at 2005 purchasing power parity (PPP) dollar divided by sector employment.

Source: Authors' calculations using GGDC data 
Figure 4. Level of Economywide Labor Productivity versus Ratio of Agricultural and Nonagricultural Productivity: USA, Chile, Thailand versus Three African Countries
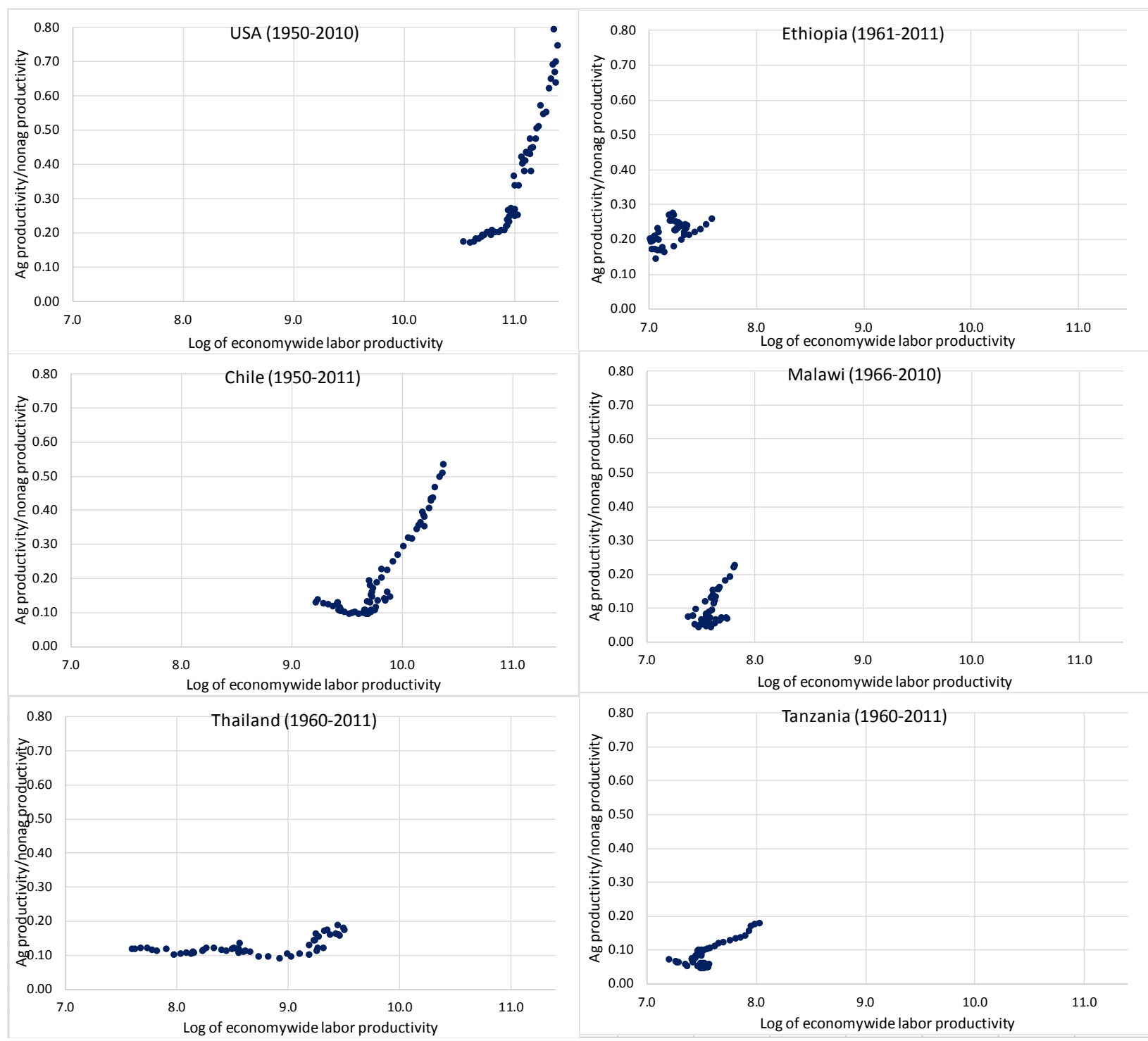

Note: Economywide labor productivity is total value-added at 2005 purchasing power parity (PPP) dollar divided by total employment. Agricultural and nonagricultural labor productivity are sectoral value-added at 2005 purchasing power parity (PPP) dollar divided by sectoral employment.

Source Authors' calculations using GGDC data. 
Figure 5. Labor Productivity Growth within Sectors and due to Structural Change, in Pre- and PostGrowth Accelerations (Annual Growth Rates, Percentages)

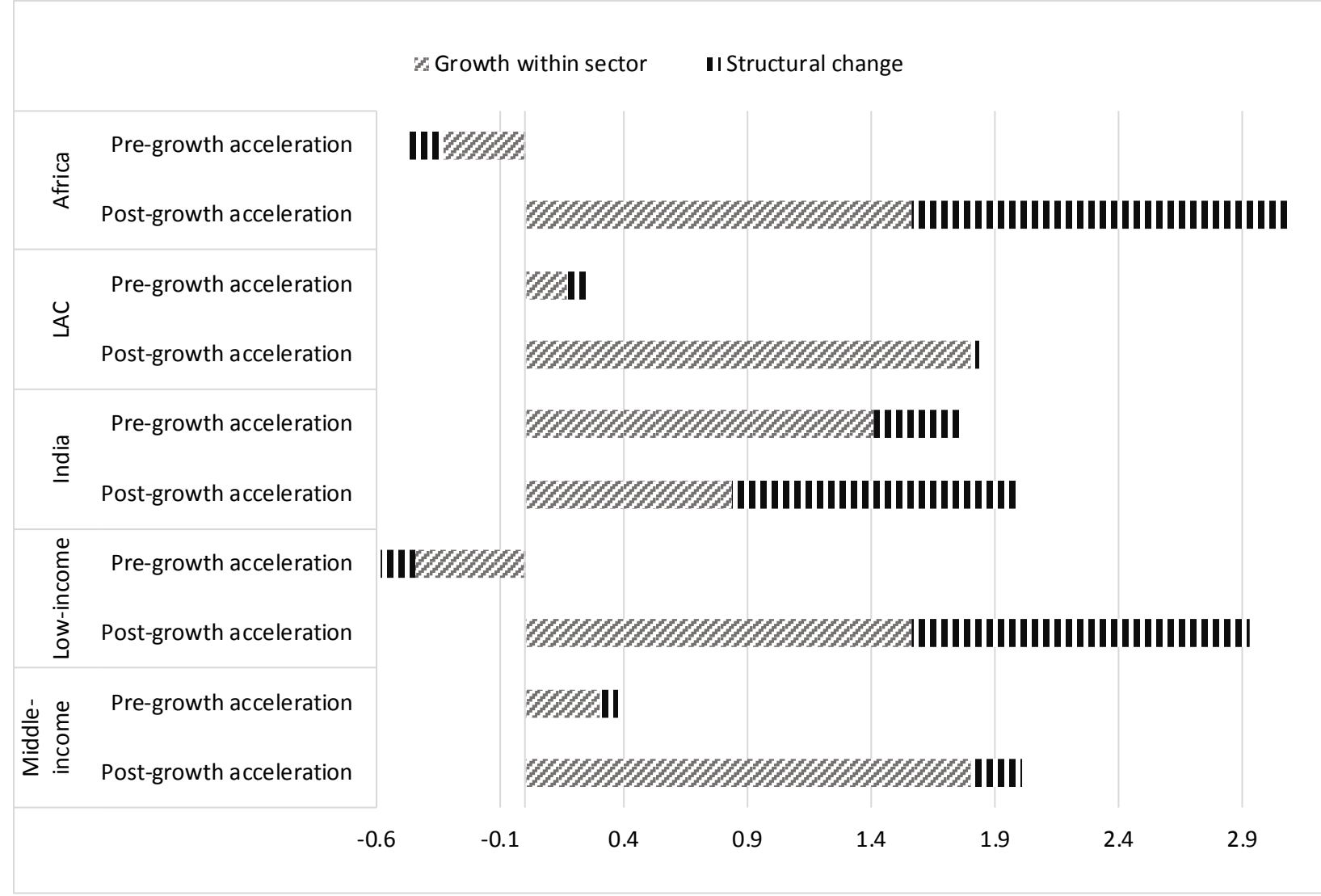

Note: The transition years from pre- to post-growth accelerations are different across countries, while the length of both pre- and post-periods are all 10 years.

The cut-off in income level between low and middle income groups is a per-capita GDP of $\$ 10,000$ in the transition years from pre- to post-growth accelerations, measured in constant 2011 USD using PWT (9.0) data. The middle income countries include all the LAC countries except for BOL, and also include ZAF, while the low-income countries include all African countries except for ZAF, and also include BOL. For the lowincome group, GDP per capita ranges from $\$ 992$ in ETH to $\$ 4,275$ in BOL. India is not included in the two income groups, and its per capita GDP per capita is $\$ 1,832$ in 1983 , the initial year of growth acceleration.

Source: Authors' calculations using GGDC data 
Figure 6. Patterns of Labor Productivity Growth within Sector and from Structural Change Post-Growth Accelerations (Measured in Percentage Points of Economywide Productivity Annual Growth)

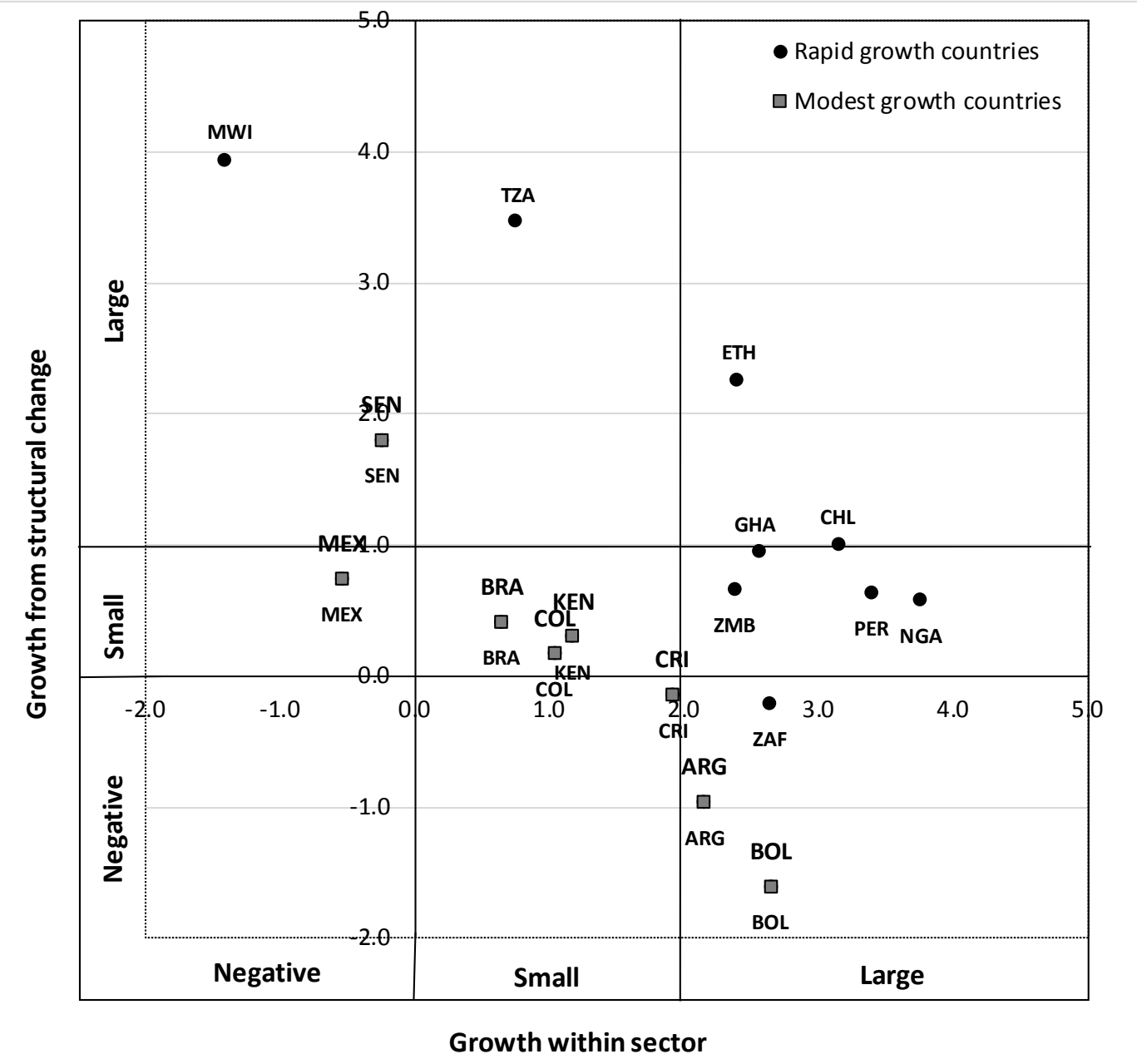

Notes: Both $\mathrm{x}$-axis and $\mathrm{y}$-axis are percentages that measure the economywide annual labor productivity growth in the 10-year period of post-growth acceleration

Dots are countries with rapid growth acceleration and squares are countries with modest growth, measured by labor productivity.

The correlation coefficient is -0.860 among the rapid growth countries, -0.907 among the modest growth countries, and -0.505 for all countries.

Source: Authors' calculations using GGDC data 
Figure 7. Differences in Productivity Growth Rates Pre- and Post-Growth Accelerations Measured by Structural Change and within Sector Terms in Percentage Points of Economywide Productivity Annual Growth

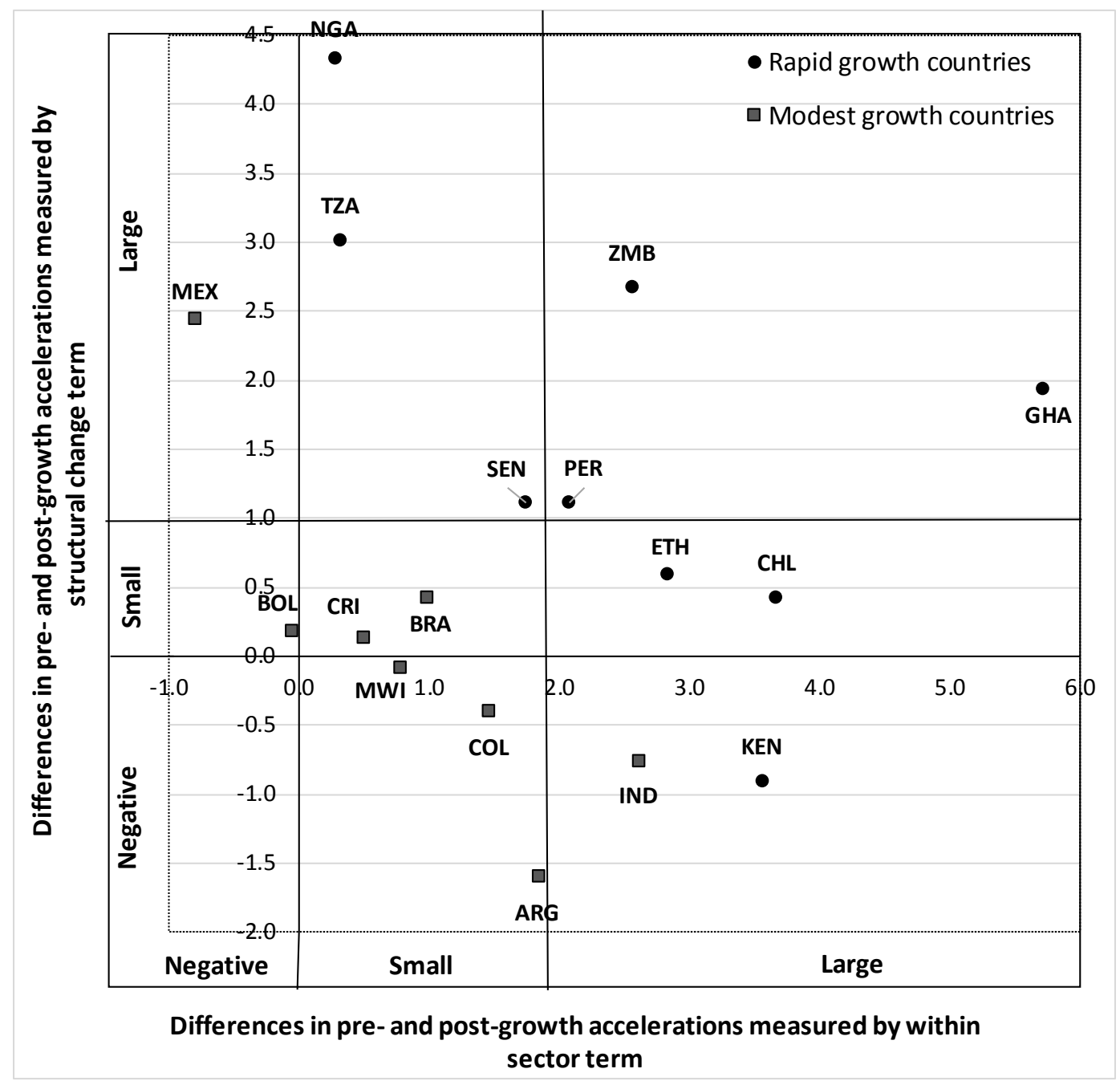

Notes: Both $\mathrm{x}$-axis and $\mathrm{y}$-axis are percentages that are the differences in economywide annual labor productivity growth rate between the periods of pre- and post-growth accelerations.

Dots are countries with rapid growth acceleration and squares are countries with modest growth acceleration measured by labor productivity.

The correlation value is -0.375 among the rapid growth countries, -0.839 among the modest growth countries, and -0.194 for all countries.

Source: Authors' calculations using GGDC data 
Figure 8. Growth Decomposition in Post-Growth Accelerations, Agricultural and Nonagricultural Growth within Sector and Economywide Structural Change (Measured in Percentage Points of Economywide Productivity Annual Growth)

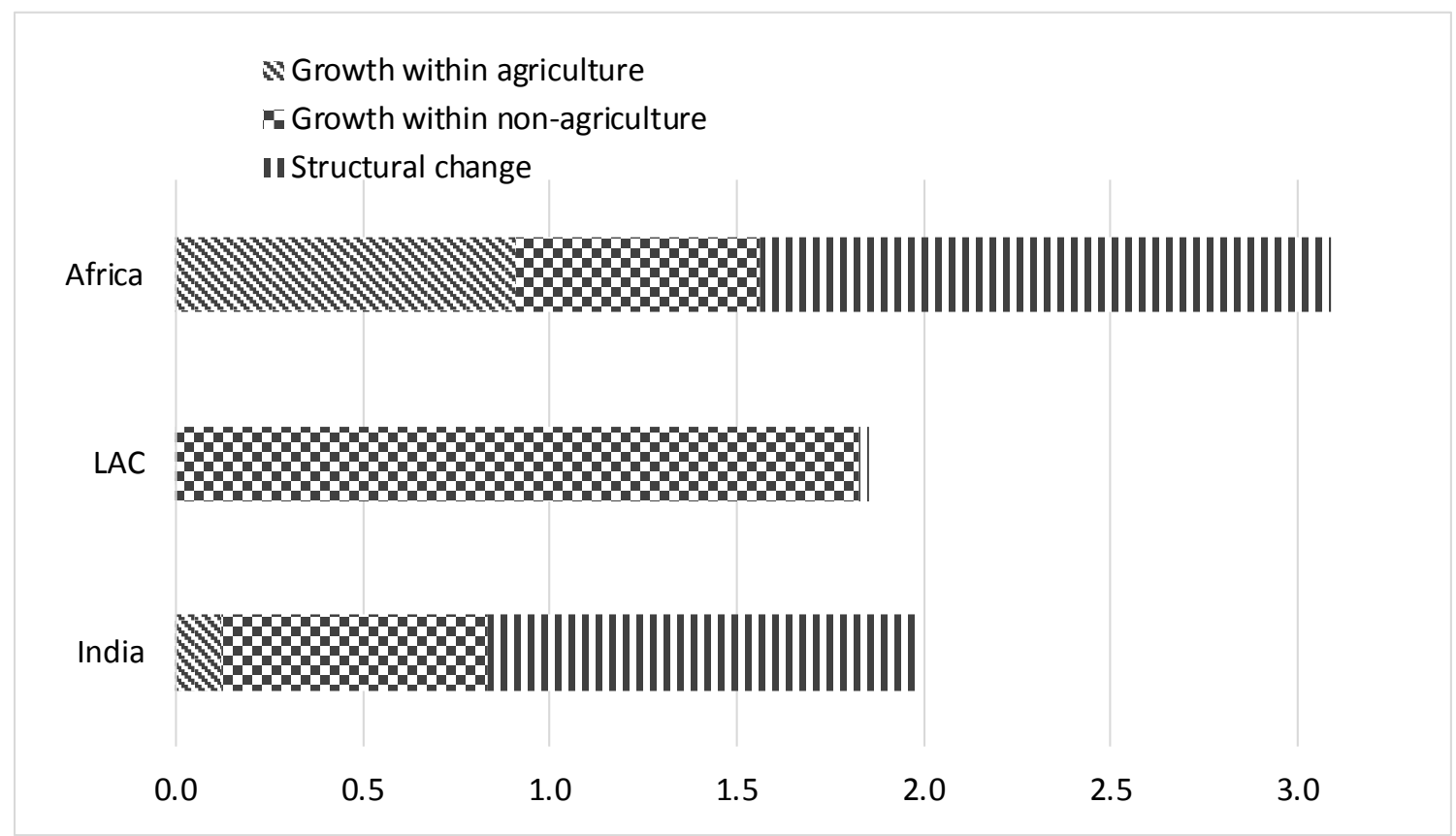

Source: Authors' calculations using GGDC data 
Figure 9. Sectoral Contributions to Economywide Labor Productivity Growth within Sector and from Structural Change during First Decade of Growth Acceleration across African Countries (Measured in Percentage Points of Economywide Productivity Annual Growth)

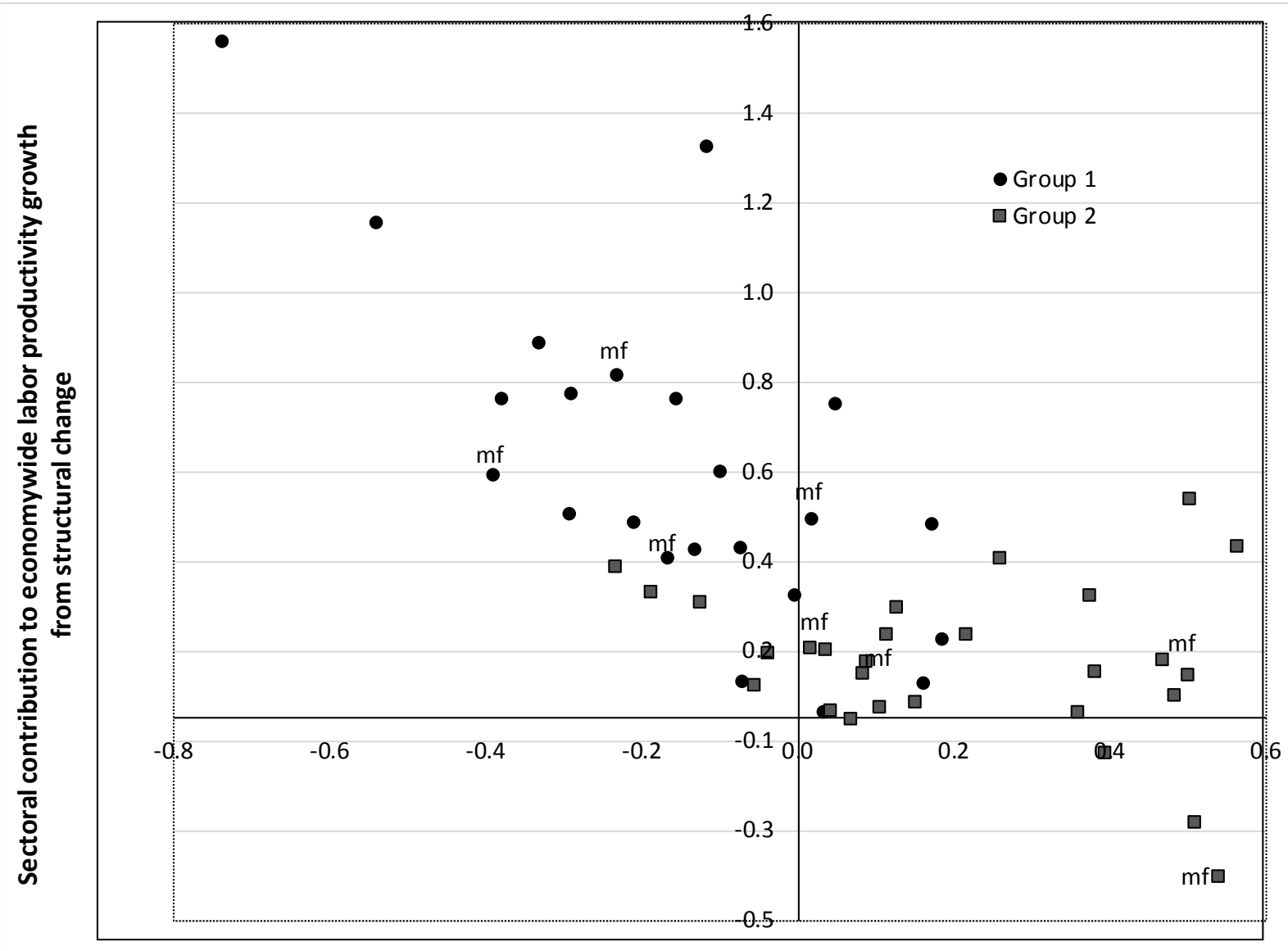

Sectoral contribution to economywide labor productivity growth within sector

Notes: "mf" represents manufacturing sector.

Structural change negatively contributes to the economywide labor productivity growth in NGA, which is excluded from the chart.

Correlation coefficients: Group 1: -0.721; Group 2: -0.246

Source: Authors' calculations using GGDC data 
Figure 10. Labor Productivity Growth within Sector and from Structural Change across Countries for Specific Nonagricultural sectors (Measured in Percentage Points of Economywide Productivity Annual Growth)

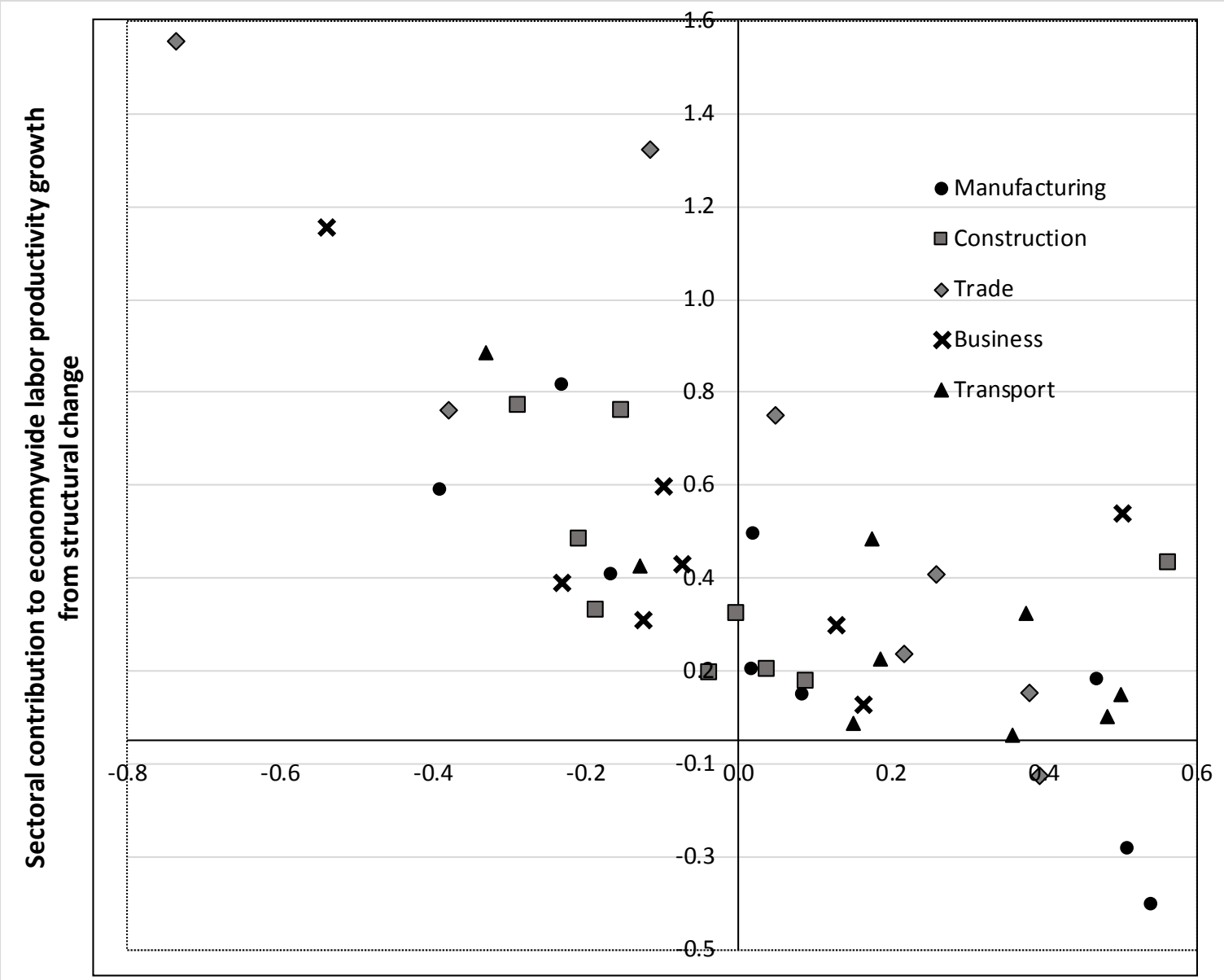

Sectoral contribution to economywide labor productivity growth within sector

Source: Authors' calculations using GGDC data 
Figure 11. Sectoral Contributions to Economywide Labor Productivity Growth within Sector and from Structural Change during First Decade of Growth Acceleration across Five Asian Countries (Measured in Percentage Points of Economywide Productivity Annual Growth)

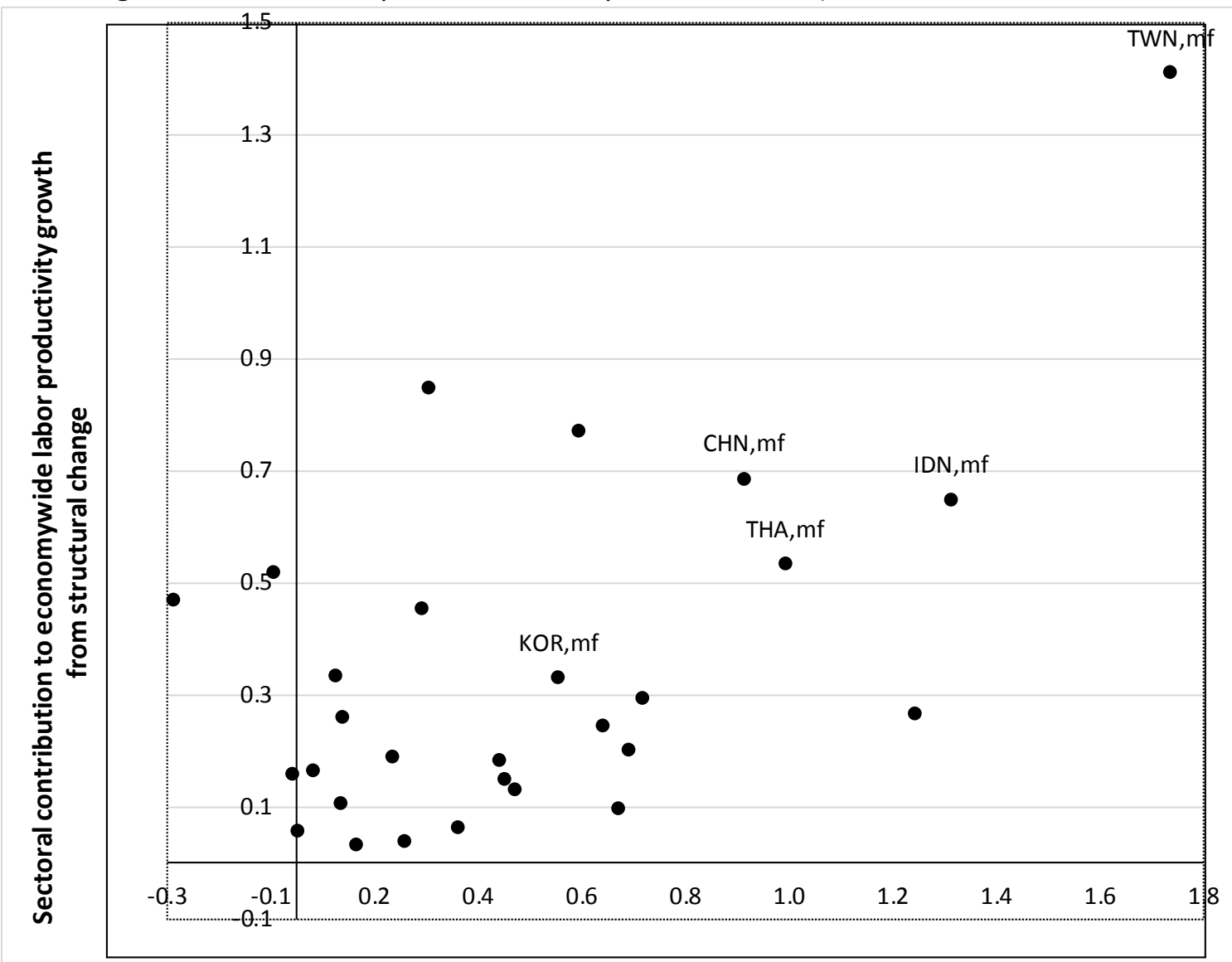

Sectoral contribution to economywide labor productivity growth within sector

Note: "mf" represents manufacturing sector.

Source: Authors' calculations using GGDC data 
Figure 12. Labor Productivity Growth within Sector and from Structural change, Four Low-Income Asian Countries (Annual Percentages)

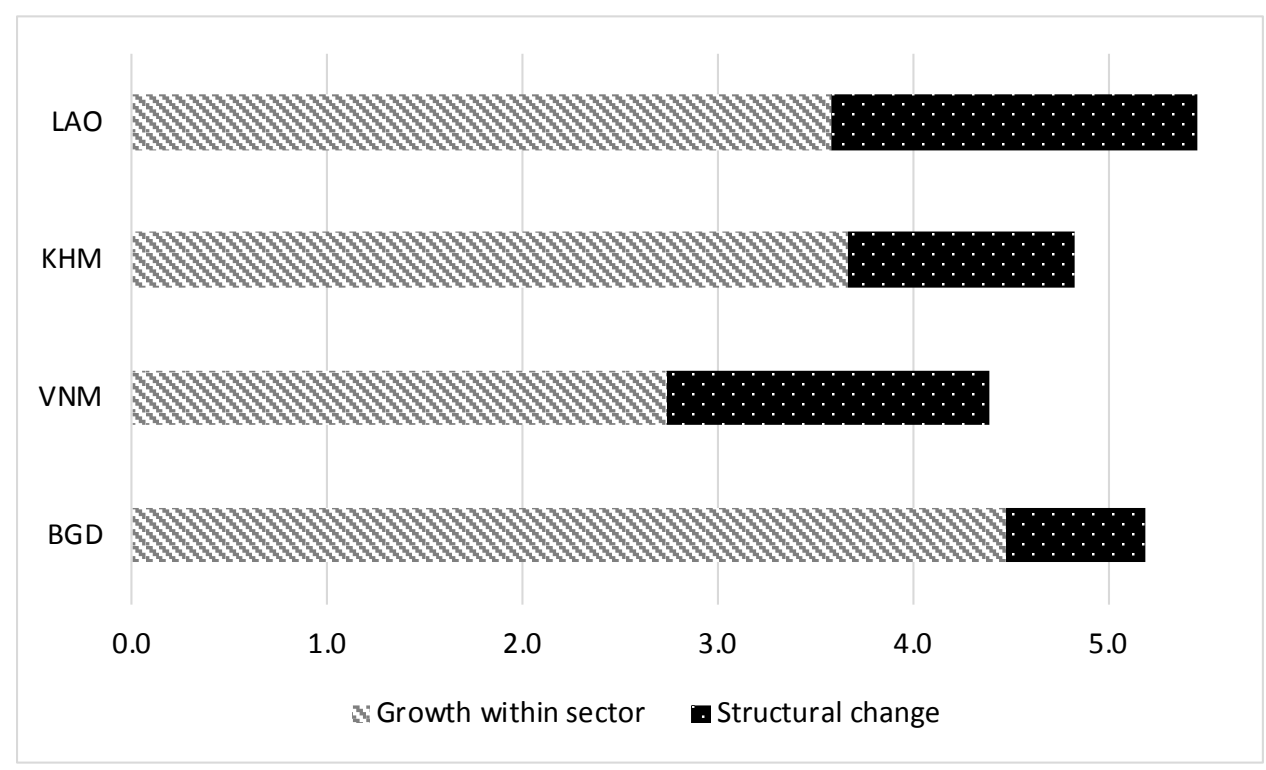

Note: The period covered is 2003-2014. See text for sources. 
Figure 13. Nonagricultural Sectors' Contribution to Growth Accelerations, Four Low-Income Asian Countries (Annual Percentages)

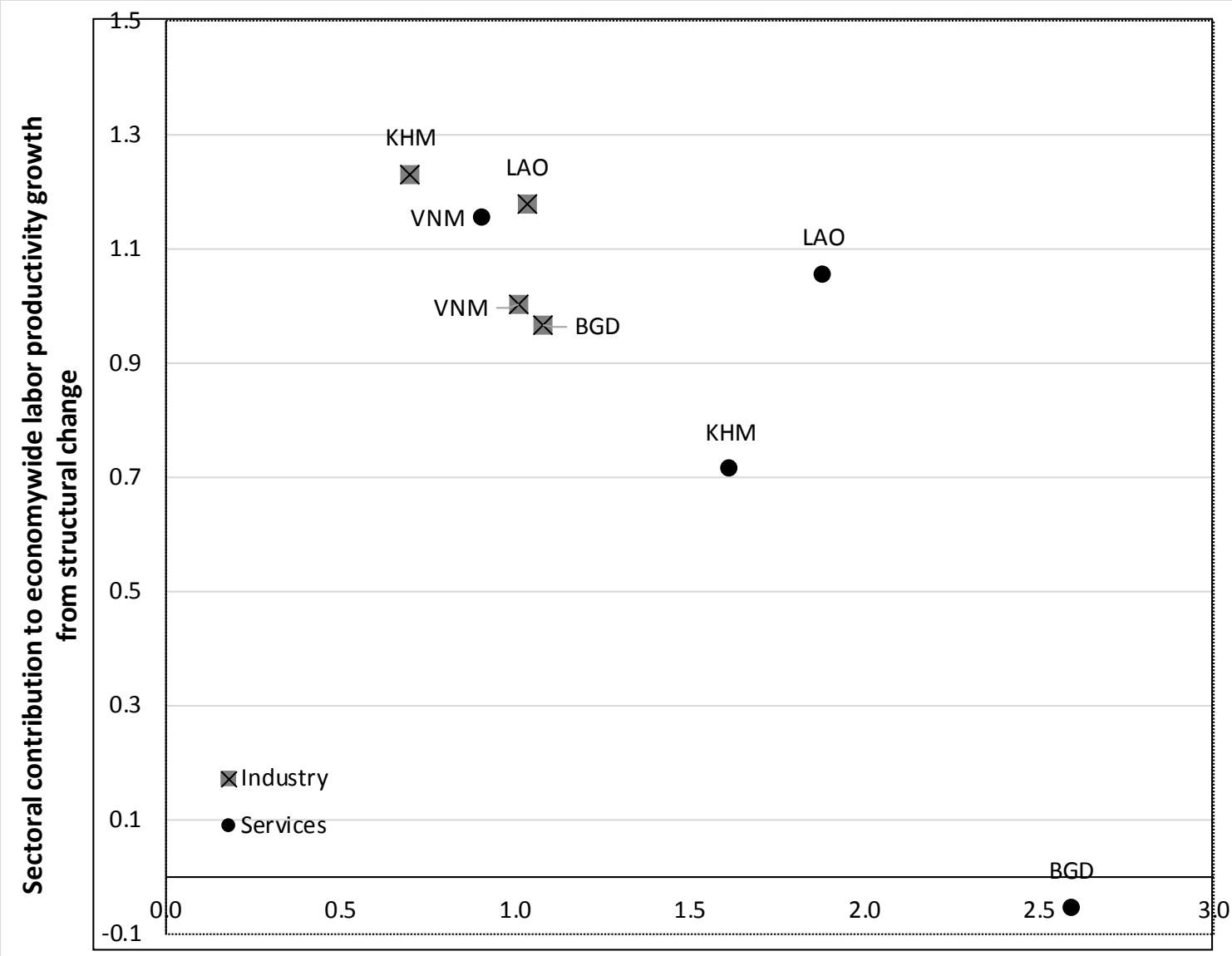

Sectoral contribution to economywide labor productivity growth within sector

Note: The period covered is 2003-2014. See text for sources. 
Figure 14. Equilibrium Allocation of Labor

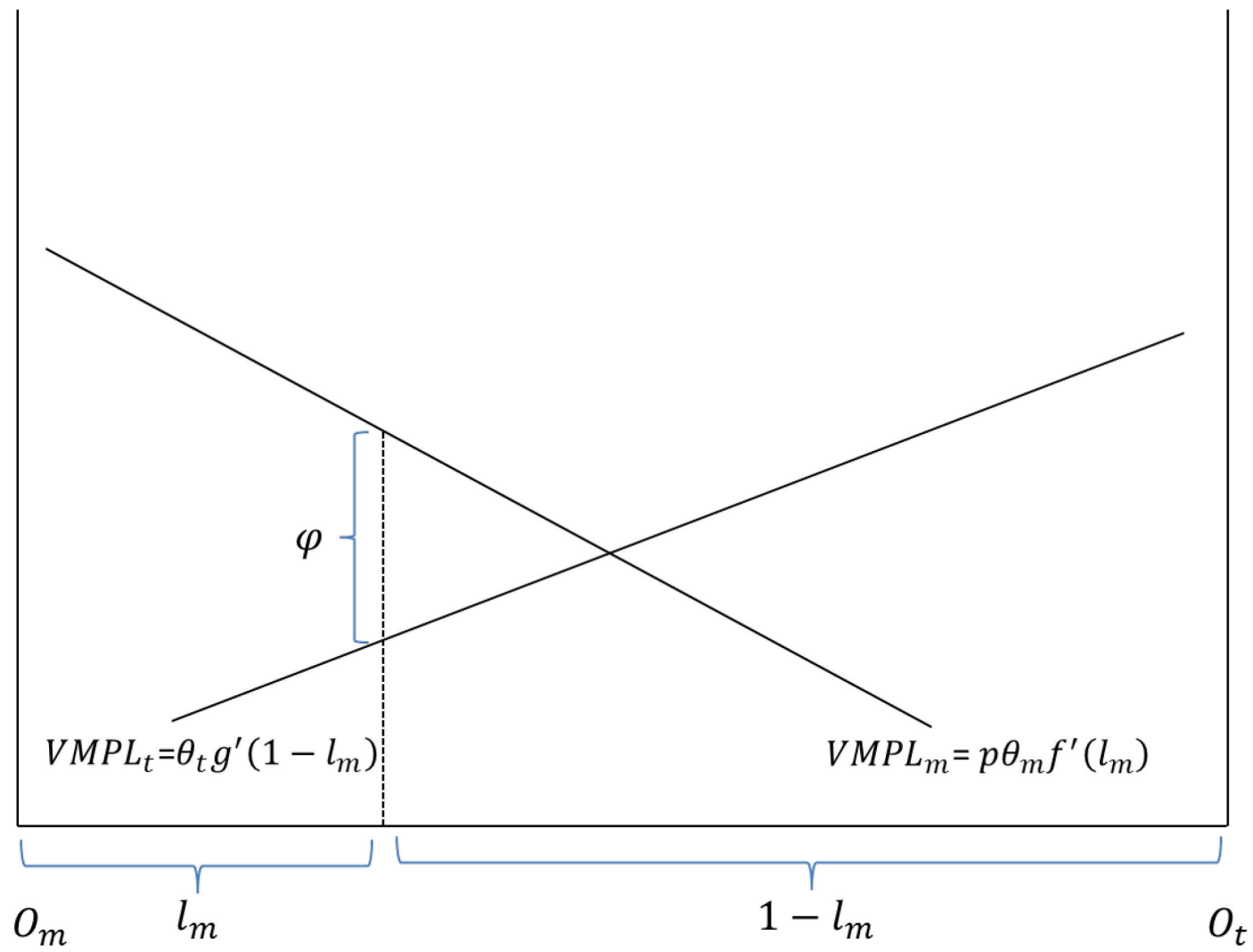


Figure 15. A Positive Supply Shock to Modern Sector

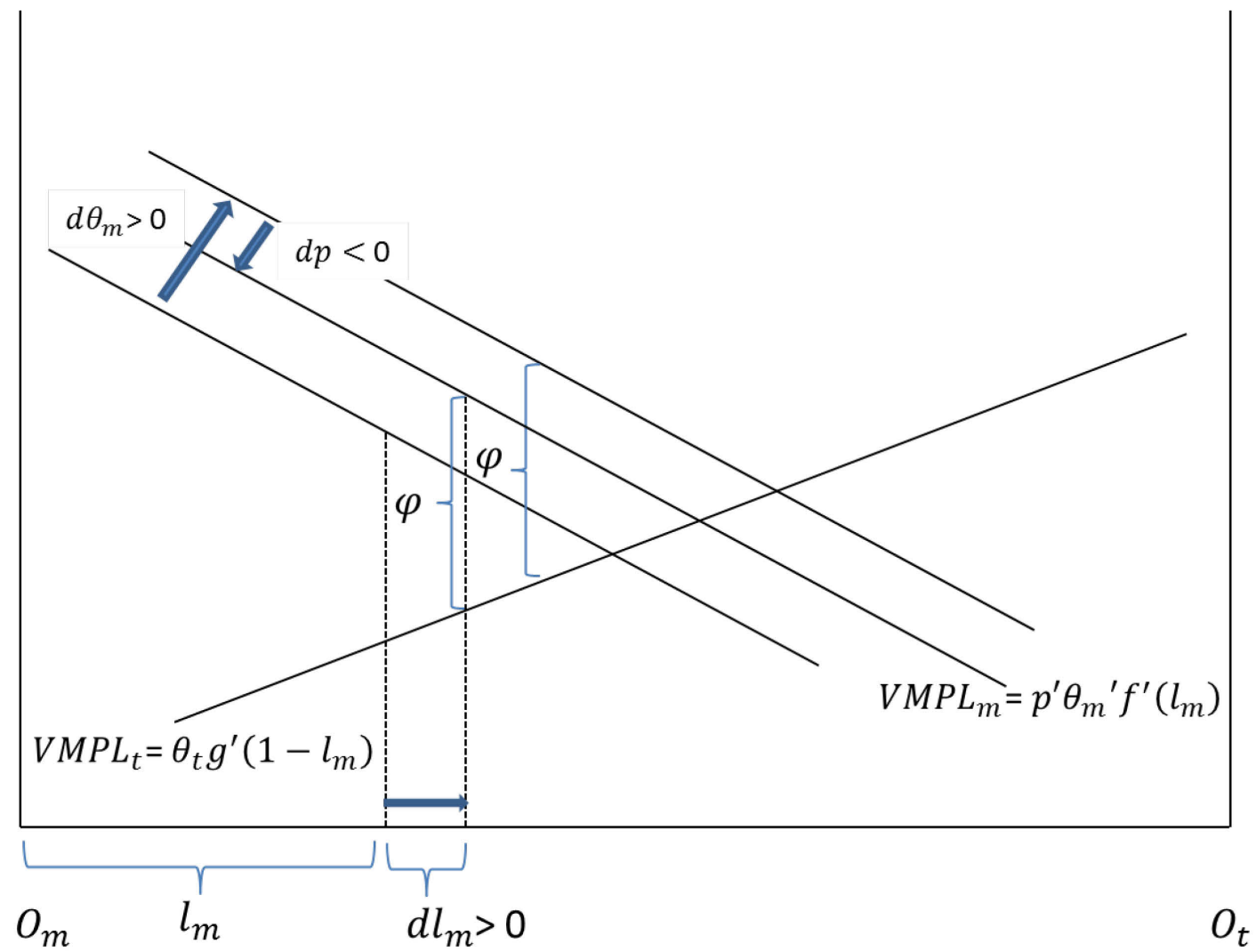


Figure 16. A Positive Productivity Shock in the Traditional Sector

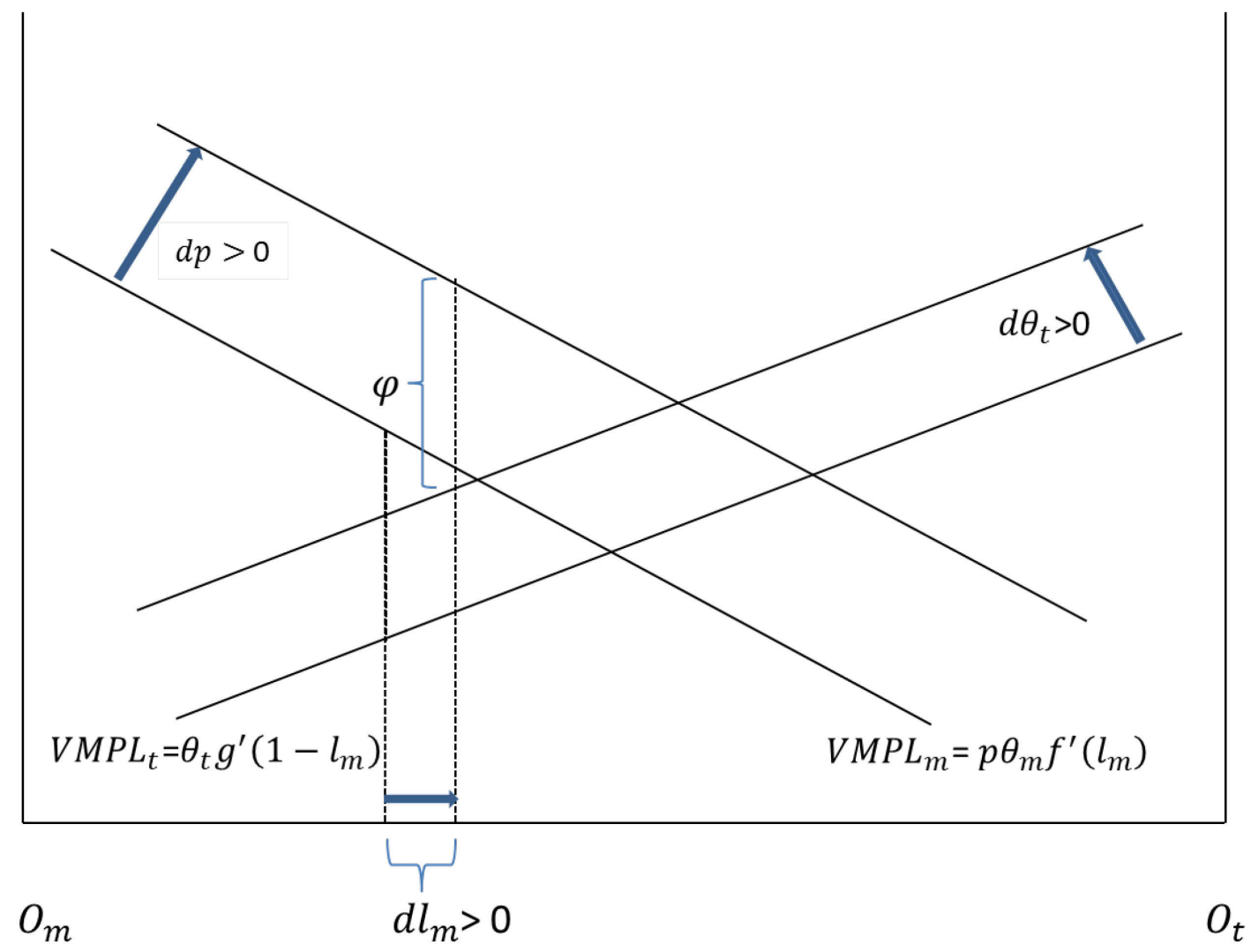


Figure 17. An Increase in Aggregate "Demand"

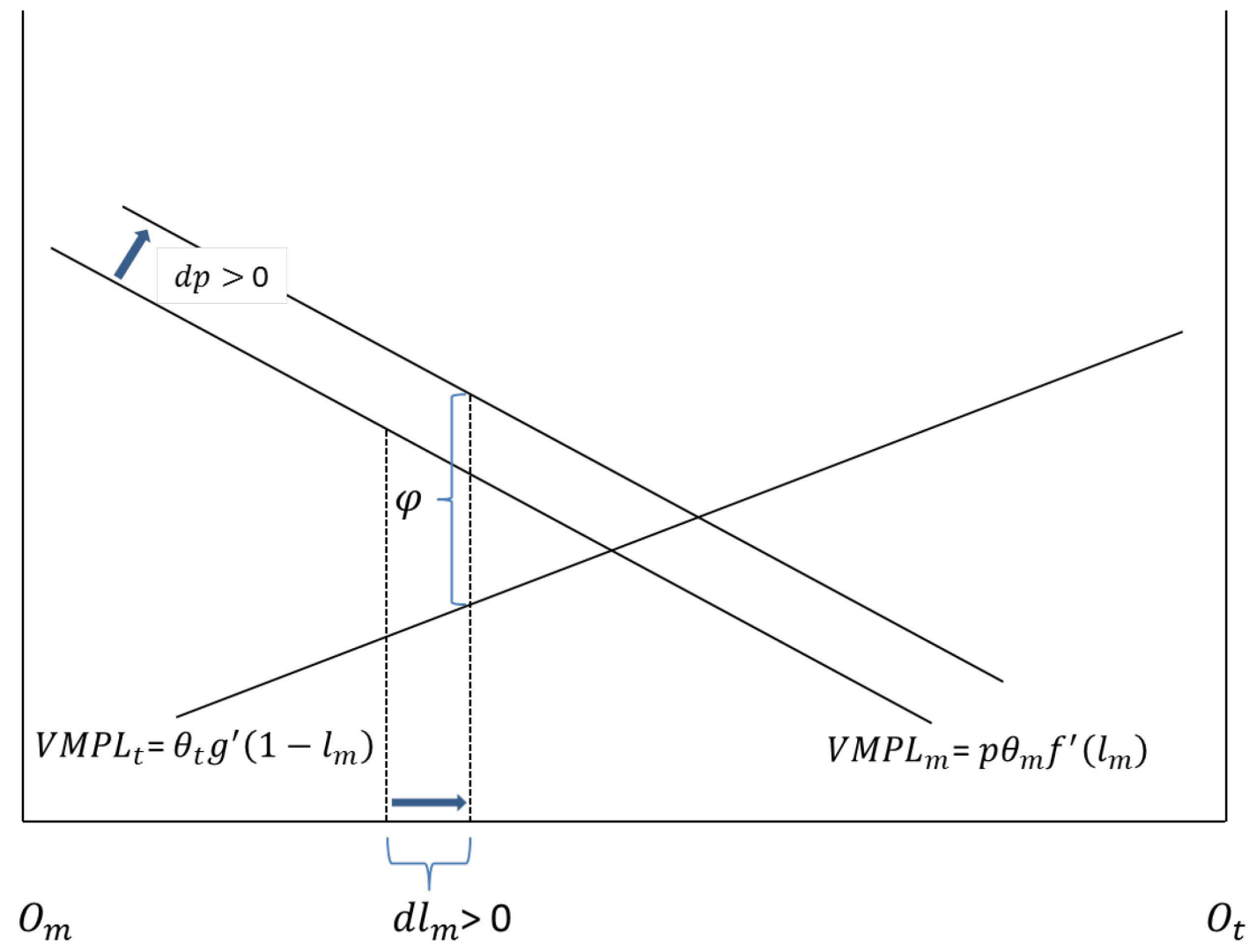


Figure 18. Domestic Relative Price of Manufacturing in Asia

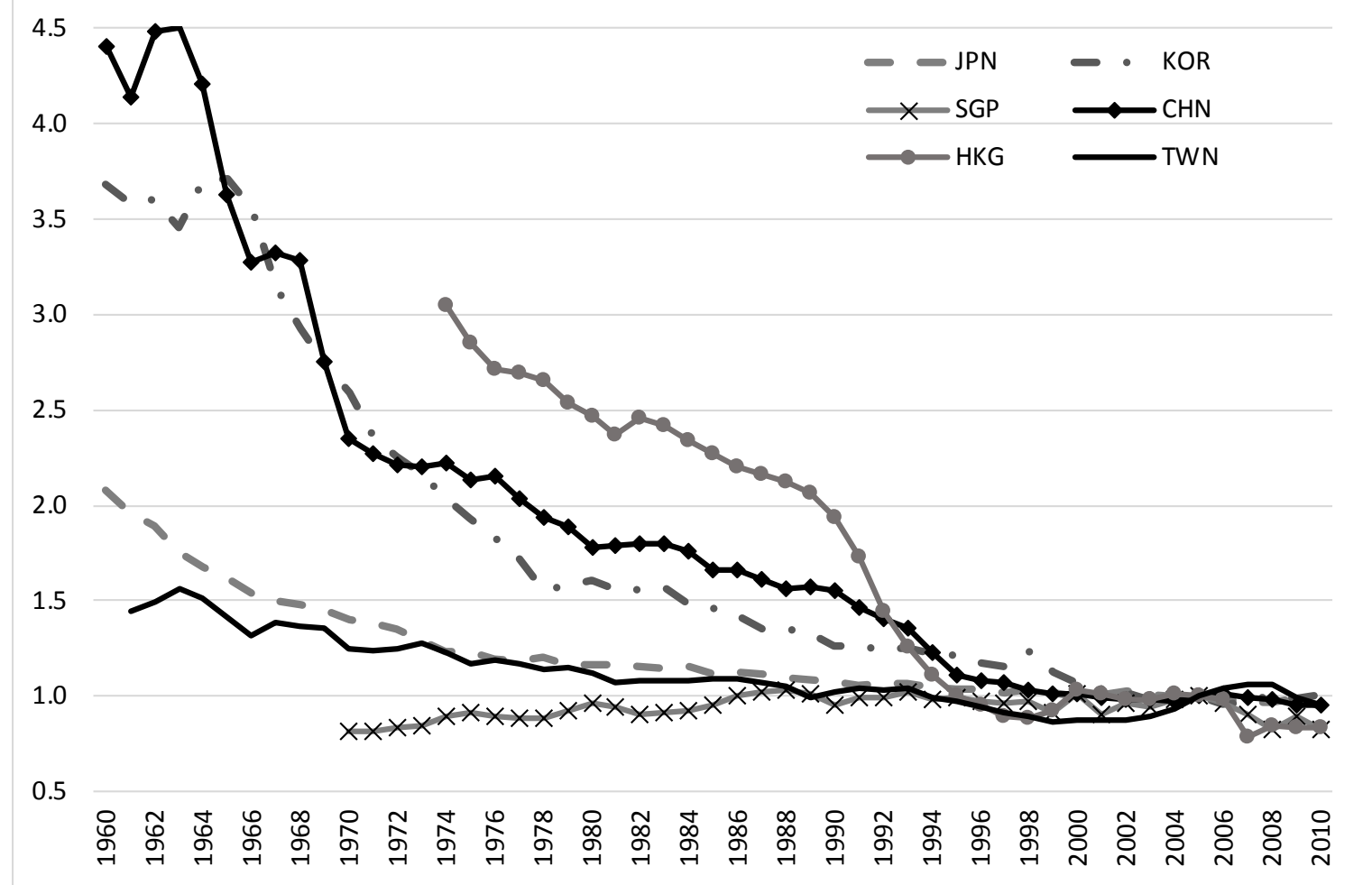

Note: Implicit prices indices are derived by taking the ratio of nominal and constant price value added series. The manufacturing price is normalized by the economywide price index.

Source: Authors' calculations using GGDC data 
Figure 19. Domestic Relative Price of Manufacturing in Africa

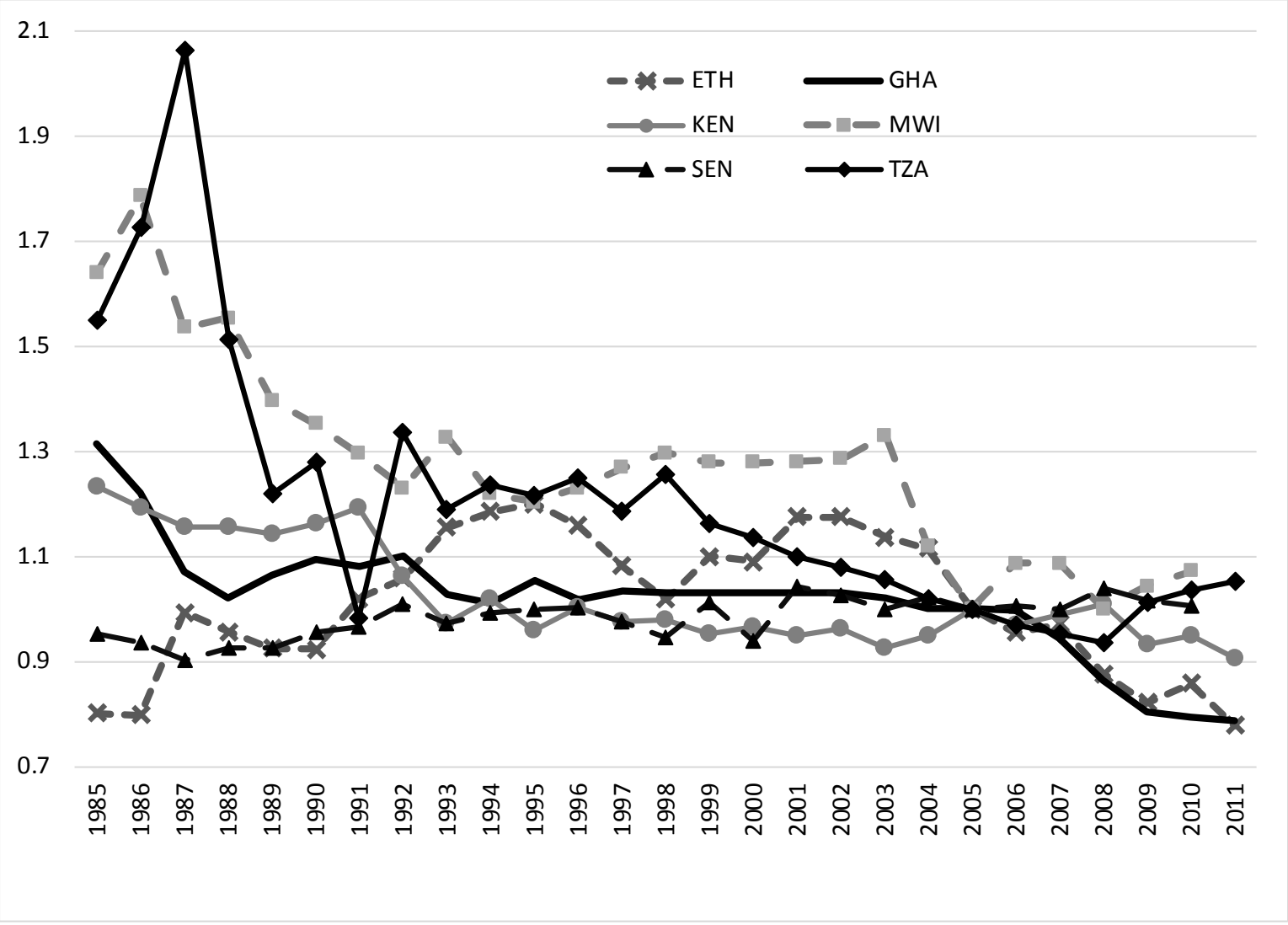

Source: Same as the previous figure. 
Figure 20. Sustained Growth in Four Countries in Each Post-Growth Acceleration Decade (Annual Percentages)

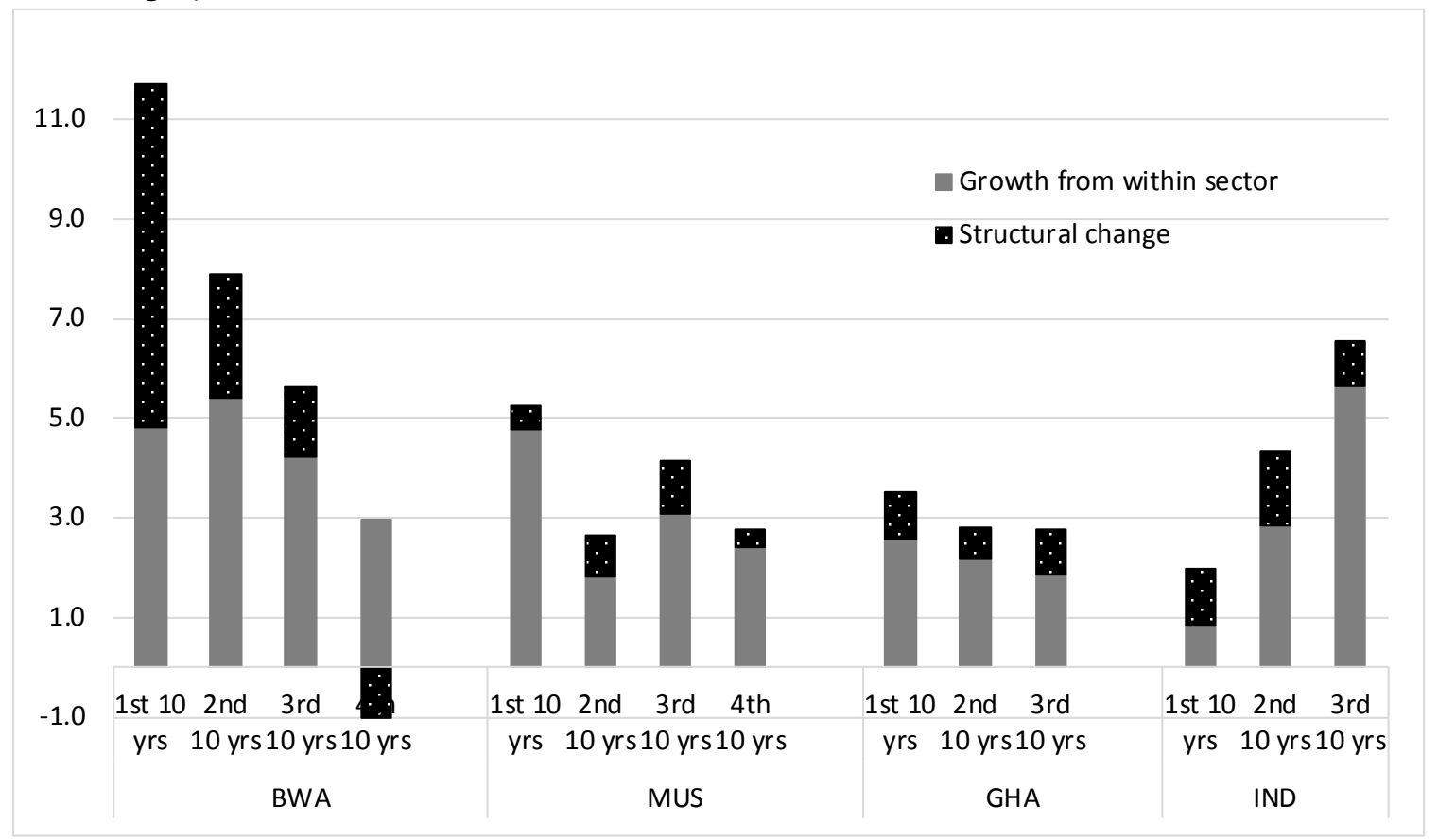

Source: Authors' calculations using GGDC data 


\section{Appendix}

\section{Methodological Notes on Growth Decompositions}

Equation (2) in Section 2 indicates that the growth decomposition is an accounting exercise which can have various economic interpretations. Besides Equation (2), there are a few different ways to decompose economywide labor productivity. In general, we are facing three sets of choices: (a) which weights to use, (b) whether to use annual data or simply period end points, and (c) how to annualize the growth rates. While aggregate labor productivity growth rates are little affected by these choices, they could influence the magnitude of labor productivity growth rates within sector and from structural change. The difference in results among the three choices disappears only in the limit where the length of a period is infinitely short.

The following discussion explains how different choices could possibly affect the magnitude of growth in both the within and between components of the growth decomposition. A few examples based on the GGDC data are also provided. We then explain our preferred methodology for decomposing labor productivity growth into its' within and between components.

Equation (A1) below is a starting point that describes a change in economywide labor productivity in a given period of $(t-k, t)$ with $k$ years:

$$
y^{t}-y^{t-k}=\Delta y^{t}=\sum_{i} y_{i}^{t} \theta_{i}^{t}-\sum_{i} y_{i}^{t-k} \theta_{i}^{t-k}
$$

where $y^{t}$ and $y^{t-k}$ are economywide labor productivity at time $t$ and $t-k$ respectively, $y_{i}^{t}$ and $y_{i}^{t-k}$ are sector $i^{\prime}$ s labor productivity at $t$ and $t-k, \theta_{i}^{t}=\frac{L_{i}^{t}}{L^{t}}$ and $\theta_{i}^{t-k}=\frac{L_{i}^{t-k}}{L^{t-k}}$ are share of labor $(L)$ employed in sector $i$ at $t$ and $t-k$, and $t>k$.

By rearranging (A1), we can express the growth decomposition as

$$
\Delta y^{t}=\sum_{i} \theta_{i}^{t-k} \Delta y_{i}^{t}+\sum_{i} y_{i}^{t} \Delta \theta_{i}^{t}
$$

or

(A3) $\quad \Delta y^{t}=\sum_{i} \theta_{i}^{t} \Delta y_{i}^{t}+\sum_{i} y_{i}^{t-k} \Delta \theta_{i}^{t}$

where $\Delta y_{i}^{t}=y_{i}^{t}-y_{i}^{t-k}$ and $\Delta \theta_{i}^{t}=\theta_{i}^{t}-\theta_{i}^{t-k}$. (A2) is identical to equation (2) in Section 2, and is the version of the decomposition most commonly used in the literature (as in McMillan and Rodrik, 2011, and de Vries, Timmer and de Vries, 2015).

In (A2), weights in the "within term" are sectors' labor shares at the beginning of the period (start-point weight) and weights in the "between term" are sectors' labor productivity at the end of the period (end-point weight). In (A3), weights are the opposite of those in (A3), i.e., the within term uses end-point weights and the between term uses start-point weights. Both $\Delta y_{i}^{t}$ and $\Delta \theta_{i}^{t}$ can be positive or negative for a given sector, while $\sum \Delta \theta_{i}^{t}=0$.

Assuming $\Delta y_{i}^{t} \neq 0$ and $\Delta \theta_{i}^{t} \neq 0$, for a given sector $i$, there are four possibilities for combined $\Delta y_{i}^{t}$ and $\Delta \theta_{i}^{t}$ with different signs, i.e., (a) $\Delta y_{i}^{t}>0 \& \Delta \theta_{i}^{t}<0$, (b) $\Delta y_{i}^{t}>0 \& \Delta \theta_{i}^{t}>0$, (c) $\Delta y_{i}^{t}<0$ \& $\Delta \theta_{i}^{t}>0$, and (d) $\Delta y_{i}^{t}<0 \& \Delta \theta_{i}^{t}<0$. Under different situations, the choice of the weights affects the magnitudes of the two components at the sector level. We consider each case below. 
Case (a): $\quad y_{i}^{t}>y_{i}^{t-k}$ and $\theta_{i}^{t}<\theta_{i}^{t-k}$. This is commonly seen for $i=$ agriculture among developing countries.

In this case, sector $i$ positively contributes to within sector growth and negatively contributes to growth from structural change. Moreover, since $\theta_{i}^{t-k} \Delta y_{i}^{t}>\theta_{i}^{t} \Delta y_{i}^{t}$ and $\left|y_{i}^{t} \Delta \theta_{i}^{t}\right|>\left|y_{i}^{t-k} \Delta \theta_{i}^{t}\right|$, compared to eq. (A3), eq. (A2) could overstate the contribution of sector i's (agricultural) within sector productivity growth and hence also overstate the negative contribution of this sector to structural change.

Case (b): $\quad y_{i}^{t}>y_{i}^{t-k}$ and $\theta_{i}^{t}>\theta_{i}^{t-k}$. This is commonly seen among East Asian countries for $i=$ manufacturing.

In this case, $\theta_{i}^{t-k} \Delta y_{i}^{t}<\theta_{i}^{t} \Delta y_{i}^{t}$ and $y_{i}^{t} \Delta \theta_{i}^{t}>y_{i}^{t-k} \Delta \theta_{i}^{t}$. Compared to eq. (A3), eq. (A2) could understate the contribution of sector i's (manufacturing) within sector productivity growth and overstate the contribution of this sector to structural change.

Case (c): $\quad y_{i}^{t}<y_{i}^{t-k}$ and $\theta_{i}^{t}>\theta_{i}^{t-k}$. We have seen this in this paper in the case of African countries for many nonagricultural sectors.

In this case, $\Delta y_{i}^{t}<0,\left|\theta_{i}^{t-k} \Delta y_{i}^{t}\right|<\left|\theta_{i}^{t} \Delta y_{i}^{t}\right|$, but $y_{i}^{t} \Delta \theta_{i}^{t}<y_{i}^{t-k} \Delta \theta_{i}^{t}$, which implies that eq. (A2) could understate both the negative contribution of sector $i$ to within-sector productivity changes and its positive contribution from structural change in comparison with eq. (A3).

Case (d): $\quad y_{i}^{t}<y_{i}^{t-k}$ and $\theta_{i}^{t}<\theta_{i}^{t-k}$, which is a rare case, but we do see it in Hong Kong for the construction sector for the period 1990-2010 in the GGDC data.

Because both $\Delta y_{i}^{t}<0$ and $\Delta \theta_{i}^{t}<0,\left|\theta_{i}^{t-k} \Delta y_{i}^{t}\right|>\left|\theta_{i}^{t} \Delta y_{i}^{t}\right|$ and $\left|y_{i}^{t} \Delta \theta_{i}^{t}\right|<\left|y_{i}^{t-k} \Delta \theta_{i}^{t}\right|$, eq. (A2) could overstate sector $i$ 's negative contribution within-sector and understate the negative contribution to structural change in comparison with eq. (A3).

The discussion of these four cases are for individual sectors. There is never a situation where all sectors of a country follow a single case, and thus, combined effects across sectors often produce ambiguity. In general, there is less concern for which equation should be used when productivity gaps across sectors are small or changes in employment structure over time are modest. In the examples shown in Figure A2, however, it is clear that the choice between these two equations affects the decomposition in the African and Latin American country groups significantly, while there is little effect for the high income country group or for Asian countries.

We have checked the robustness of the main findings discussed in the body of the paper by comparing them with the results when we use eq. (A3) instead of eq. (A2). As expected, we get a somewhat different quantitative decomposition into the between and within terms. But we still have a negative correlation between the magnitudes of the within and between terms. In addition, Latin America's growth acceleration is due overwhelmingly to the improvement in the within terms, while Africa's is due to the between terms, as discussed.

The second and third choices related to the growth decomposition exercise are whether we just calculate changes in labor productivity growth within sector and from structural change in a given period (e.g., over 10 years) as shown in eqs. (A2) or (A3), or whether we compute their annual growth rates. Reporting annual growth rates in labor productivity growth within sector and from structural change has 
the advantage that we can relate these to annual growth rates in GDP as we do in Table 4 of this paper. A commonly used method is to first get the changes in within and between terms across sectors over an entire period, and then annualize them to get an average annual growth rate. This method is used by McMillan and Rodrik (2011) and de Vries, Timmer and de Vries (2015). One advantage of this method is that we only need value-added and employment data across sectors at two data points (two years). The disadvantage is that when time series data are available, this method simply ignores all the data between the initial and end points in a growth decomposition analysis. Again, when sectoral labor productivity and shares of employment do not fluctuate over time and follow a monotonic trend in growth (a trend either up or down) during the period in question, different methods of annualizing matter little. Indeed, we do not see much difference for the two different methods of annualizing the data for the high income and Asian country groups, but there are some differences for African countries (Figure A3).

In this paper, we focus on recent growth accelerations in African and Latin American countries. Therefore, we decided to use a year-by-year calculation using the weights defined in eq. (A2) but to calculate each year's growth rate for the within and between components at sector level across countries as follows:

$$
g_{y}^{t}=\sum_{i} \theta_{i}^{t-1} \pi_{i}^{t-1} g_{y_{i}}^{t}+\sum_{i} \Delta \theta_{i}^{t} \pi_{i}^{t-1}\left(1+g_{y_{i}}^{t}\right) .
$$

where $g_{y}^{t}=\frac{\Delta y^{t}}{y^{t-1}}, g_{y_{i}}^{t}=\frac{\Delta y_{i}^{t}}{y_{i}^{t-1}}$, and $\pi_{i}^{t}$ is relative labor productivity for sector $i$ defined as $\pi_{i}^{t}=\frac{y_{i}^{t}}{y^{t}}$. We then calculate the average annual growth rates for the within and between terms in a given period (e.g., over 10 years) for each sector by taking a simple average as follows:

$$
\bar{g}_{i}^{\text {within }}=\frac{1}{10} \sum_{t=1}^{10} \theta_{i}^{t-1} \pi_{i}^{t-1} g_{y_{i}}^{t}
$$

and

$$
\bar{g}_{i}^{\text {between }}=\frac{1}{10} \sum_{t=1}^{10} \Delta \theta_{i}^{t} \pi_{i}^{t-1}\left(1+g_{y_{i}}^{t}\right)
$$

where $\bar{g}_{i}^{\text {within }}$ and $\bar{g}_{i}^{\text {between }}$ are the average labor productivity growth rates of sector $i$ within sector and from structural change in a given 10-year period, and where both $\bar{g}_{i}^{\text {within }}$ and $\bar{g}_{i}^{\text {between }}$ are measured as fractions of the average annual growth rate of economywide labor productivity in this period. Thus, the annual economywide labor productivity growth rate and its two components in this given period are defined as follows:

$$
\bar{g}=\sum_{i} \bar{g}_{i}^{\text {within }}+\sum_{i} \bar{g}_{i}^{\text {beween }}
$$

Table A1 below presents $\bar{g}, \sum_{i} \bar{g}_{i}^{\text {within }}$, and $\sum_{i} \bar{g}_{i}^{\text {beween }}$ at the country level, while the details for $\bar{g}_{i}^{\text {within }}$ and $\bar{g}_{i}^{\text {between }}$ at the sector level across countries can be obtained from the authors upon request. 


\section{Appendix Tables and Figures}

Table A1. Growth Decomposition Before and After Growth Accelerations (10 Years in Each Period, Percentage Points, Annual Average)

\begin{tabular}{|c|c|c|c|c|c|c|}
\hline & \multicolumn{2}{|c|}{ Labor productivity growth } & \multicolumn{2}{|c|}{ Within sector } & \multicolumn{2}{|c|}{$\begin{array}{l}\text { Between sector } \\
\text { (structural change) }\end{array}$} \\
\hline & $\begin{array}{l}\text { Before growth } \\
\text { accel'n }\end{array}$ & $\begin{array}{l}\text { After growth } \\
\text { accel'n }\end{array}$ & $\begin{array}{l}\text { Before growth } \\
\text { accel'n }\end{array}$ & $\begin{array}{l}\text { After growth } \\
\text { accel'n }\end{array}$ & $\begin{array}{l}\text { Before growth } \\
\text { accel'n }\end{array}$ & $\begin{array}{l}\text { After growth } \\
\text { accel'n }\end{array}$ \\
\hline & $(t-9, t)$ & $(t, t+9)$ & $(t-9, t)$ & $(t, t+9)$ & $(t-9, t)$ & $(t, t+9)$ \\
\hline ARG & -0.66 & 1.19 & -0.46 & 2.15 & -0.21 & -0.96 \\
\hline $\mathrm{BOL}$ & 0.81 & 1.04 & 0.81 & 2.65 & 0.00 & -1.61 \\
\hline BRA & 0.94 & 1.06 & 0.71 & 0.65 & 0.23 & 0.41 \\
\hline $\mathrm{CHL}$ & 0.05 & 4.15 & -0.52 & 3.15 & 0.57 & 1.00 \\
\hline $\mathrm{COL}$ & -0.19 & 1.21 & 0.06 & 1.04 & -0.25 & 0.17 \\
\hline CRI & 0.73 & 1.78 & 0.47 & 1.92 & 0.26 & -0.14 \\
\hline MEX & -0.43 & 0.20 & -1.04 & -0.54 & 0.60 & 0.74 \\
\hline PER & 0.84 & 4.03 & 1.32 & 3.40 & -0.48 & 0.64 \\
\hline ETH & 1.22 & 4.65 & -0.44 & 2.40 & 1.66 & 2.25 \\
\hline GHA & -4.13 & 3.51 & -3.15 & 2.56 & -0.98 & 0.95 \\
\hline KEN & -1.17 & 1.48 & -2.38 & 1.18 & 1.21 & 0.30 \\
\hline MWI & 0.88 & 2.52 & -0.62 & -1.41 & 1.49 & 3.93 \\
\hline NGA & -0.27 & 4.34 & 3.49 & 3.76 & -3.75 & 0.58 \\
\hline SEN & -1.30 & 1.56 & -1.98 & -0.24 & 0.69 & 1.80 \\
\hline ZAF & 1.75 & 2.44 & 1.87 & 2.65 & -0.12 & -0.21 \\
\hline TZA & 0.89 & 4.23 & 0.43 & 0.76 & 0.46 & 3.47 \\
\hline ZMB & -2.18 & 3.04 & -0.17 & 2.38 & -2.01 & 0.66 \\
\hline LAC average & 0.26 & 1.83 & 0.17 & 1.80 & 0.09 & 0.03 \\
\hline Africa average & -0.48 & 3.09 & -0.33 & 1.56 & -0.15 & 1.53 \\
\hline India & 1.77 & 1.99 & 1.41 & 0.84 & 0.36 & 1.16 \\
\hline Middle-income & 0.38 & 2.01 & 0.30 & 1.80 & 0.08 & 0.20 \\
\hline Low-income & -0.58 & 2.93 & -0.44 & 1.56 & -0.14 & 1.37 \\
\hline
\end{tabular}

Notes: The numbers are in percentage points, measured in terms of economywide annual labor productivity growth, i.e., the economywide labor productivity growth in the first two columns equal the sum of growth from within sector versus structural change terms in columns 3-4 and columns 5-6.

Source: Authors' calculations using GGDC data 
Figure A1. Labor Productivity Growth within Sector and from Structural Change in Five Asian Countries in Their First 10 Years Post-Growth Accelerations (Measured in Percentage Points of Economywide Productivity Annual Growth)

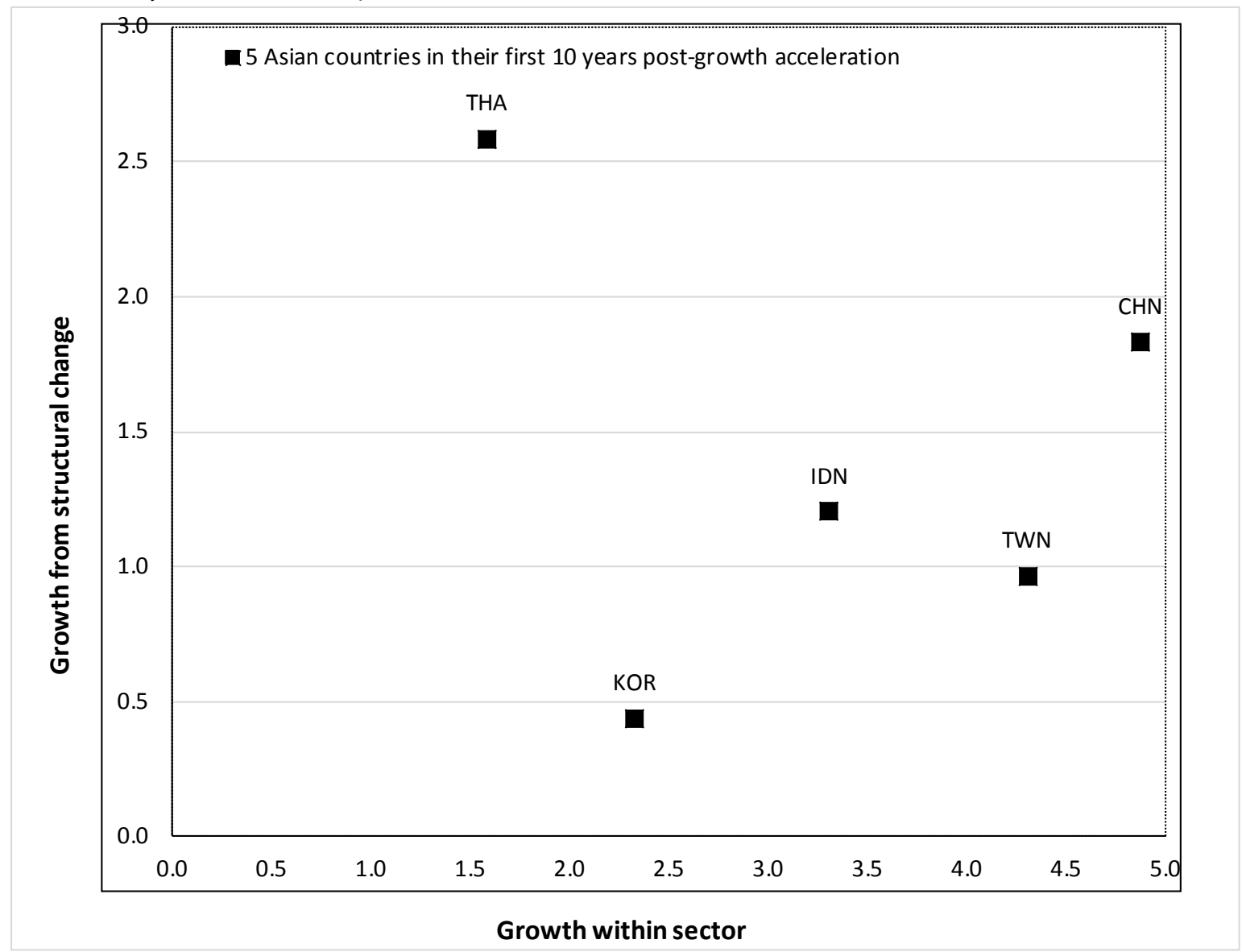

Source: Authors' calculations using GGDC data 
Figure A2. Comparison of Two Methods in Equations (A2) and (A3) for Labor Productivity Growth in 2000-2010 (Percentages)

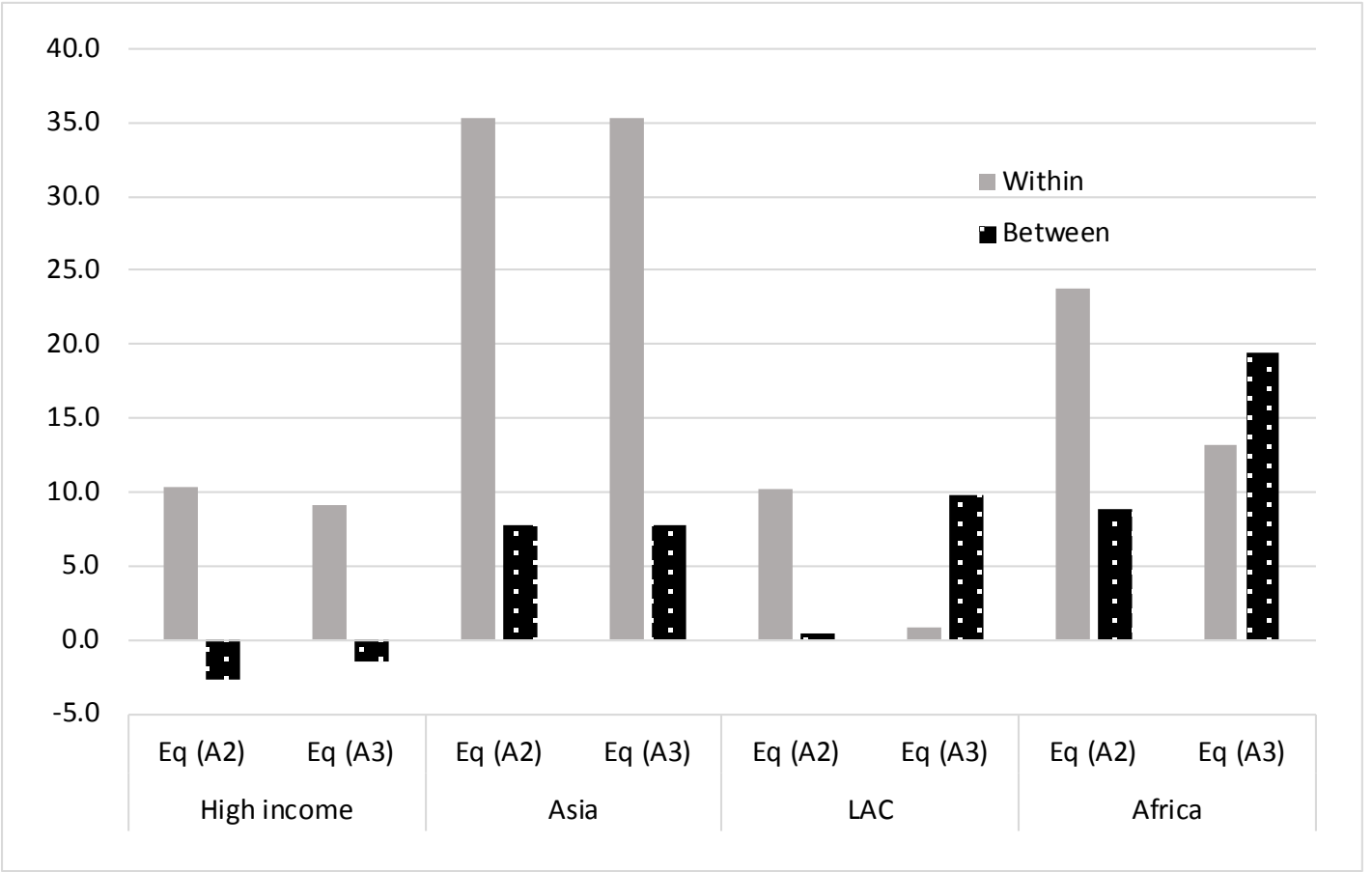

Source: Authors' calculations using GGDC data

Figure A3. Comparison of Different Approaches to Annualize Labor Productivity Growth Rate in 20002010 (Percentages)

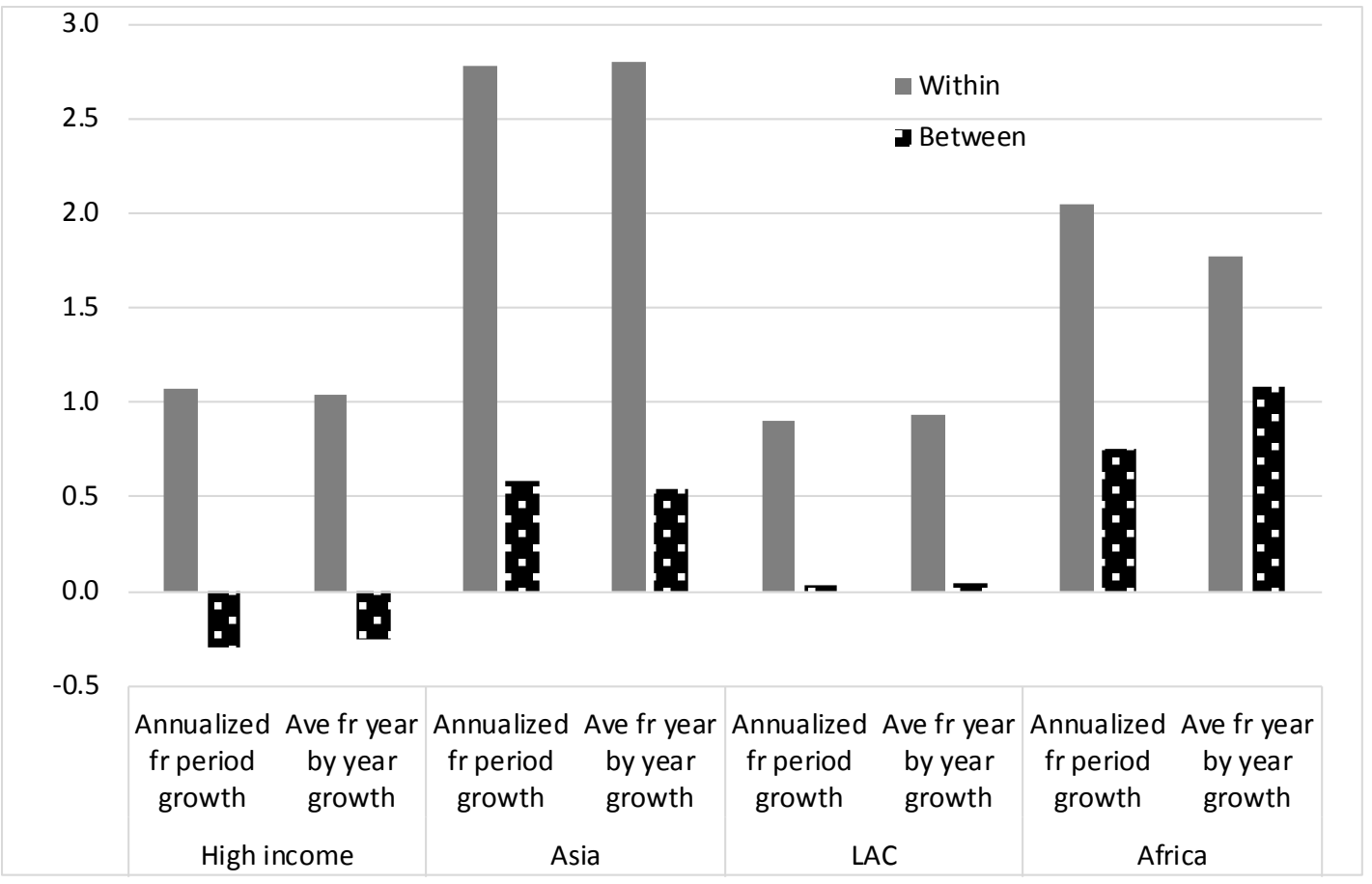

Noe: Equation (2) is used in both approaches.

Source: Authors' calculations using GGDC data 